\title{
The Traditional Chinese Medicine and Relevant Treatment for the Efficacy and Safety of Atopic Dermatitis: A Systematic Review and Meta-Analysis of Randomized Controlled Trials
}

\author{
Zhao-feng Shi, ${ }^{1}$ Tie-bing Song, ${ }^{2}$ Juan Xie, ${ }^{1}$ Yi-quan Yan, ${ }^{1}$ and Yong-ping Du ${ }^{1}$ \\ ${ }^{1}$ Department of Traditional Chinese Medicine, Xijing Hospital Affiliated to Fourth Military Medical University, Xian 710032, China \\ ${ }^{2}$ Department of Orthopaedics, Xian City Hospital of Traditional Chinese Medicine, Xi'an 710021, China \\ Correspondence should be addressed to Yong-ping Du; ddyypp@fmmu.edu.cn
}

Received 3 February 2017; Accepted 16 May 2017; Published 21 June 2017

Academic Editor: Farzad Deyhim

Copyright (C) 2017 Zhao-feng Shi et al. This is an open access article distributed under the Creative Commons Attribution License, which permits unrestricted use, distribution, and reproduction in any medium, provided the original work is properly cited.

\begin{abstract}
Background. Atopic dermatitis (AD) has become a common skin disease that requires systematic and comprehensive treatment to achieve adequate clinical control. Traditional Chinese medicines and related treatments have shown clinical effects for AD in many studies. But the systematic reviews and meta-analyses for them are lacking. Objective. The systematic review and meta-analysis based on the Preferred Reporting Items for Systematic Reviews and Meta-Analyses (PRISMA) statement were conducted to evaluate the efficacy and safety of traditional Chinese medicines and related treatments for AD treatment. Methods. Randomized controlled trials (RCTs) were searched based on standardized searching rules in eight medical databases from the inception up to December 2016 and a total of 24 articles with 1,618 patients were enrolled in this meta-analysis. Results. The results revealed that traditional Chinese medicines and related treatments did not show statistical differences in clinical effectiveness, SCORAD amelioration, and SSRI amelioration for AD treatment compared with control group. However, EASI amelioration of traditional Chinese medicines and related treatments for $\mathrm{AD}$ was superior to control group. Conclusion. We need to make conclusion cautiously for the efficacy and safety of traditional Chinese medicine and related treatment on AD therapy. More standard, multicenter, double-blind randomized controlled trials (RCTs) of traditional Chinese medicine and related treatment for $\mathrm{AD}$ were required to be conducted for more clinical evidences providing in the future.
\end{abstract}

\section{Introduction}

Atopic dermatitis (AD) is a common chronic, inflammatory, and pruritic noncontagious superficial skin disease, affecting approximately up to $25 \%$ of children and $2 \%$ to $3 \%$ of adults and making the incidence rate reach a peak compared with the past few years [1]. The situation in China is also severe: $8.3 \%$ of children aged between 3 and 6 years are wrecked by this disease [2]. AD brings much financial burden to the world countries on this condition: in the United States, for instance, the national expenditure for $\mathrm{AD}$ ranged from $\$ 364$ million to $\$ 3.8$ billion dollars [3]. The combined factor of etiological candidate genes (CTLA4, IL18, TLR9, CARD4, $\mathrm{TGF} \beta 1$, etc.) and environment (food, sweating, stress, temperature, etc.) is the main etiology of atopic dermatitis $[4,5]$.
The pathogenesis of $\mathrm{AD}$ is still unclear nowadays, but some studies illustrate that the Th2 cell-related cytokines, chemokines, and eotaxin might be the dominant mechanisms of $\mathrm{AD}[1,6]$.

The current diagnostic criterion of $\mathrm{AD}$ was proposed by Hanifin and Rajka in 1980 [7]. China applies the Williams diagnostic criteria for $\mathrm{AD}$ where the specificity and sensibility are same as Hanifin and Rajka criteria $[8,9]$. If physicians want to evaluate the severe degree of $\mathrm{AD}$, SCORing Atopic Dermatitis (SCORAD), Eczema Area and Severity Index (EASI), and computerized visual analogue scale (VAS) are recommended as severity system $[10,11]$. The SCORAD is the well-accepted international criterion among them, including several elements and degrees such as the area of rash, the severity of rash (erythema, exudation, lichenification, etc.) 
and the personal symptom feeling (pruritus, agrypnia, etc.) [12]. The AD treatment is based on the precise diagnostics by physicians and personal assessment by patients. The patients who were beset by $\mathrm{AD}$ should understand how to keep away from stimulating factors, such as dust mite and pollen and protect skin from dryness, injury, or infection, through reasonable measures. The first-line therapy of AD contains emollients, topical steroids, topical immunosuppressant, topical nonsteroidal anti-inflammatory drugs (NSAIDs), and oral medicine (antihistaminics, steroid, or immunosuppressant) [12-15]. The adverse effects of these methods are obvious: the topical steroid can bring folliculitis, skin atrophy, striae, erythema, and infection; burning stimulation, infection, and skin cancer can present in patients who applied immunosuppressant; patients applying the antihistaminics can suffer convulsion, day mouth, vomiting, and abnormal liver function $[16,17]$. Physicians have tried many possible alternative medical ways in order to avoid the adverse effects mentioned above. The symbolic examples of alternative medicines for $\mathrm{AD}$, including traditional Chinese medicine and related therapy, ultraviolet radiation, and psychological therapy, have brought benefit to patients to a certain degree.

Traditional Chinese medicine has a long applying history in China for AD therapy [18]. The relevant treatment of TCM, such as acupuncture and moxibustion, could also help $\mathrm{AD}$ patients to alleviate their suffering. Although amount of published randomized controlled trials and systematic reviews have evaluated the TCM and relevant treatment for $\mathrm{AD}$, the efficacy and safety are still unclear and evaluating criteria are limited $[19,20]$. Owning to the long history and wide spreading of TCM, many classical TCM prescriptions have changed their names and obtained diversified national characteristics.

Hwangryunhaedoktang, the prescription in Korea applying for $\mathrm{AD}$ therapy, actually derived from the ancient (the Eastern Jin Dynasty) Chinese medical book named Zhouhoufang [21]. Acupuncture and moxibustion have played an essential role as a complementary and alternative medicine (CAM) therapy for allergy relief (itch, asthma, and allergic rhinitis) and could be recommended for AD therapy. There were no systematic review and meta-analysis articles that evaluated the effectiveness and safety of TCM and relevant treatment as an integral part for AD therapy. So we conducted a systematic review and meta-analysis to investigate the evidence of TCM and related treatment for AD treatment.

\section{Methods}

This systematic review and meta-analysis was based on the guidelines of the Preferred Reporting Items for Systematic Reviews and Meta-Analyses (PRISMA) statement [22].

2.1. Search Protocol. Because of the pervasive low literature quality in Chinese electronic databases, so the international mainstreamed electronic databases including PubMed, Embase, Science Direct, Medline, Web of Science, ProQuest, Springerlink, and Wiley Library Online were selected for articles extraction from their inception up to December 2016 by two reviewers' (Zhao-feng Shi, Yi-quan Yan) cooperation.
There were no language restrictions on literature searching in the selected database. The searching terms were conducted as follows: "allergic dermatitis", "contact dermatitis", "urticaria", "drug eruption", "eczema", "traditional Chinese medicine", "Chinese herbal medicine", "Chinese medicine", "acupuncture", "moxibustion", "random", "randomized controlled trial", and the related synonyms; meanwhile the term searching process also conducted the free text strategy and Medical Subject Headings (MeSH) term. The searching language was slightly adjusted based on the demand of different databases for adaptation. The hand searching process was also performed in the library of Fourth Military Medical University through the magazines to identify other potential related articles. Figure 1 clearly illustrated the literature identification, inclusion, and exclusion.

2.2. Studies Selection. This studies selection was conducted by two reviewers (Zhao-feng Shi, Tie-bing Song) to ensure the quality of searching. The disagreement was resolved by the third reviewers (Juan Xie) or repeated discussion. Eligible literatures were included in the meta-analysis if they suited the following criteria: (1) full-text randomized controlled trials; (2) participants of any age or gender diagnosed with $\mathrm{AD}$ or its relevant diseases (contact dermatitis, urticaria, drug eruption, eczema, etc.); (3) no active skin exudation or infection was found before experiment; (4) experimental group: patients who received traditional herbal medicine and related preparations or formula, acupuncture and moxibustion, and any treatment having the TCM characteristics, combined or not with the western medical therapy; (5) control group: participants who received placebo or western medicines; (6) all included patients having the need to stop the previous applied topical steroid or immunosuppressant at least 1 week before RCT was conducted; (7) more than 1 severe degree criterion of $\mathrm{AD}$ as follows: SCORAD, EASI, VAS, simple scoring system, the Children's Dermatology Life Quality Index (CDLQI) [23], and itch intensity; (8) the major clinical outcome effectiveness of $\mathrm{AD}$ that was evaluated having one indicator at least as follows: (a) clinical effects; (b) the median clinical scores variation; (c) laboratory index; (d) the variation of symptom scores; (e) adverse effects; (f) lesion size change. Studies would be excluded if they do not meet the criteria mentioned above or the following: (1) severe clinical illnesses (such as liver or kidney disease) or infections; (2) absence or inconsistency of methods and results; (3) case report, comments, reviews, editorials, letters, and so forth.

2.3. Data Extraction and Quality Analysis. The literature data were extracted by two independent reviewers (Zhao-feng Shi, Yi-quan Yan) who deeply assessed the article inclusion and exclusion criteria based on the modern standardized procession. All discrepancies divided by two reviewers were judged by a third reviewer (Juan Xie) until they drew the final conclusion. The literature characteristics comprised the following items: (1) the name of author and the year of publication; (2) sample size (experimental group/control group); (3) participants' age; (4) participants' gender (experimental group/control group); (5) study design; (6) disease category; (7) diagnostic and evaluating criteria; (8) treating 


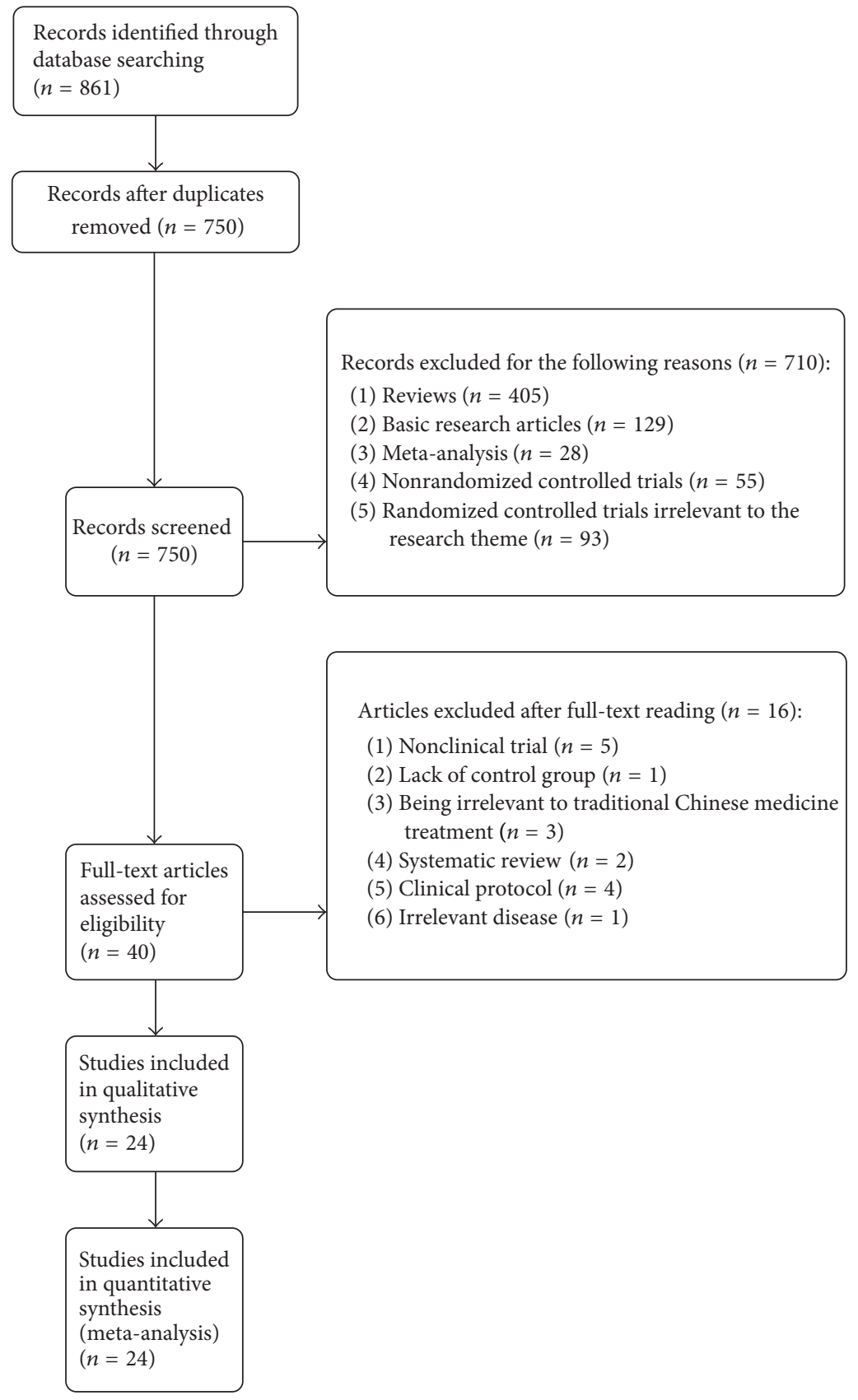

FIgURE 1: The Preferred Reporting Items for Systematic Reviews and Meta-Analyses (PRISMA) flow diagram.

method; (9) treating duration; (10) dropout numbers; (11) major outcome parameter; (12) side effect. The authors of included articles were contacted if we could not obtain the literature characteristics mentioned before (Table 1).

Two independent investigators (Zhao-feng Shi, Tie-bing Song) conducted the study quality analysis based on the Cochrane Collaboration's tools for the risk of bias assessment [24]. This tool contained six domains for the literature's evaluation: (a) the random allocation method; (b) the allocation concealment; (c) the blinding method; (d) the outcome data integrity; (e) the outcome data of selective reports; (f) other bias sources. The study sheet was conducted which contained the evaluating criteria named "Y," "N," and "U" ("Y" refers to "yes," "N" refers to "no," and " $U$ " refers to "unclear"). If one included study had three or more "Y," this study could be recognized as being of high quality which has low risk of bias, and vice versa. The literature data were collected and analyzed efficiently by the software Review Manager (RevMan; version 5.2; the Nordic Cochrane Center, the Cochrane Collaboration, 2012 Copenhagen, Denmark) and presented at table (Table 2).

2.4. Statistical Analysis. Data of articles were pooled and analyzed by the software Review Manager (RevMan; version 5.2; 
the Nordic Cochrane Center, the Cochrane Collaboration, 2012 Copenhagen, Denmark). The risk ratio (RR) with 95\% confidence interval (CI) for dichotomous outcomes and the Standard Mean Difference (Std. MD) or Mean Difference (MD) with 95\% confidence interval (CI) for continuous outcomes was calculated, respectively, by the author (Zhaofeng Shi) and repeating verified by the author (Yi-quan Yan). The calculation of $I^{2}$ statistic was applied for the statistical heterogeneity for the purpose of explanation of potential inconsistency across the included studies. It was a quantitative tool that could provide an estimate of variation resulting from heterogeneity. If the result of $I^{2}$ statistic is between $25 \%$ and $50 \%$, it would be recognized as being of low heterogeneity; the result between $50 \%$ and $75 \%$ would be of moderate heterogeneity and above $75 \%$ would be of high heterogeneity. The result of $I^{2}$ statistic that exceeded $50 \%$ was regarded as obtaining the heterogeneity according to the Cochrane Handbook (version 5.1.0) notation [25]. When the heterogeneity did not exist or was moderate, a fixed-effects model applying the Mantel-Haenszel method was performed to analyze data; when the heterogeneity was high, a random effects model applying the Der Simonian-Laired method was conducted $[26,27]$. The subgroup and sensitive analysis was adopted on the condition of high data heterogeneity in order to find the source of heterogeneity. The publication bias was evaluated by funnel plot, Egger's test, and Begg's test through the Stata (version 11.0, StataCorp LP, College Station, US): the asymmetry of image in visual appearance or $P$ value lower than 0.05 in Egger's test or Begg's test calculation could be considered as having the publication bias $[28,29]$.

\section{Results}

The article flowchart for inclusion and exclusion of metaanalysis was presented on Figure 1. A total of 861 potential literatures were identified according to the search strategies from 8 electronic databases. Of these potential articles, one hundred and eleven articles were excluded for duplication and further 710 publications were excluded for the following reasons: (1) four hundred and five studies were reviews; (2) one hundred and twenty-nine studies were basic research articles; (3) twenty-eight studies were meta-analysis; (4) fiftyfive studies were nonrandomized controlled trials; (5) ninetythree studies were randomized controlled trials but did not meet the article theme. Forty full-text articles were assessed for eligibility and 16 of them were excluded after full-text reading: (1) five studies were nonclinical trials; (2) one study lacked control group; (3) three studies were unrelated to traditional Chinese medicine therapy; (4) two articles were systematic reviews; (5) four studies were clinical protocols; (6) one study focused on irrelevant disease. Overall, a total of 24 articles of 1,618 patients were enrolled in this meta-analysis [30-53] (Table 1).

3.1. The Characteristics and Quality Evaluation of Included Articles. Table 1 clearly illustrates details and characteristics of included 24 articles. From the table, articles were grouped based on the sample size, age, gender, study design, disease category, diagnosis and evaluating criteria, treating methods, treating duration, dropout, major outcome parameters, and side effects. These articles were all strictly randomized controlled trials (RCTs) and conducted in different areas around the world. Of the final included articles, one was performed in the United Kingdom (UK) [30], one in India [36], one in Japan [40], one in Korea [46], one in Iran [52], one in the United States [47], three in Germany [41, 44, 48], and fifteen in China [31-35, 37-39, 42, 43, 45, 49-51, 53]. The year of publishing for articles was between 1992 and 2016. Overall, five hundred and seventy-eight people with $\mathrm{AD}$ (experimental) and 533 people without $\mathrm{AD}$ (control) contributed to the meta-analysis, whereas 5 articles did not show the group dividing situation (507 people) [30, 31, 33, 41, $48,51]$. The age of included people disturbed by AD had a wide range from infant to elderly people. The diagnostic and evaluating criterion of $\mathrm{AD}$ in different centers did not reach an agreement and kept diversified. The SCORAD [34, 43, 44, $46,48,50,51]$ and the Hanifin and Rajka criteria $[36,42,43$, $46,51-53$ ] were major diagnostic and evaluating criteria of studies. Traditional herbal medicine and related preparations $[30,31,33-37,40,42,43,46,49,51,53]$, acupuncture and related needling methods [32, 39, 41, 44, 45, 47, 48, 50], and Chinese herbal medicine extraction $[36,52]$ were the applied traditional Chinese medicines and related treatments of included articles in experimental groups. Treating duration of included articles was diversified ranging from 4 days to 5 months and all articles reported the treating duration. As for side effects, thirteen articles were not reported for any reasons $[32,38-41,44-50,53]$. Our reviewers of meta-analysis had tried to contact the authors by e-mail but did not get useful information.

For all included studies in Table 2, random collection methods were perfectly presented and the major method was performed by random number table. Thirteen articles provided the allocation concealment method $[30,31,34,36$, 40-44, 46-48, 51, 52] and eleven articles showed the blinding method [30, 31, 34, 40, 41, 43, 44, 46, 48, 51, 52]. All outcome data of included trials were integrity. Only one included article did not conform to the outcome data of selective report because the outcomes were merely presented by $P$ value without specific outcome data supporting [39]. For the part of no other bias source, one article did not accord with it because there were a small number of subjects in each group, leaving the possibility that the results may have been due to chance or other bias [47]. Figures 2 and 3 were conducted by the software RevMan, both supporting the data of Table 2 . Two reviewers (Zhao-feng Shi and Yi-quan Yan) conducted Tables 1 and 2 separately and disagreements of them were discussed with the third reviewer (Juan Xie) until the final same conclusion was made.

\subsection{Meta-Analysis}

3.2.1. Clinical Effectiveness. Figure 4 showed the clinical effectiveness of traditional Chinese medicines and relevant treatments for atopic dermatitis (AD) therapy. Eight articles which were all carried out in China including 667 participants were analyzed in the forest plot of meta-analysis. For the 


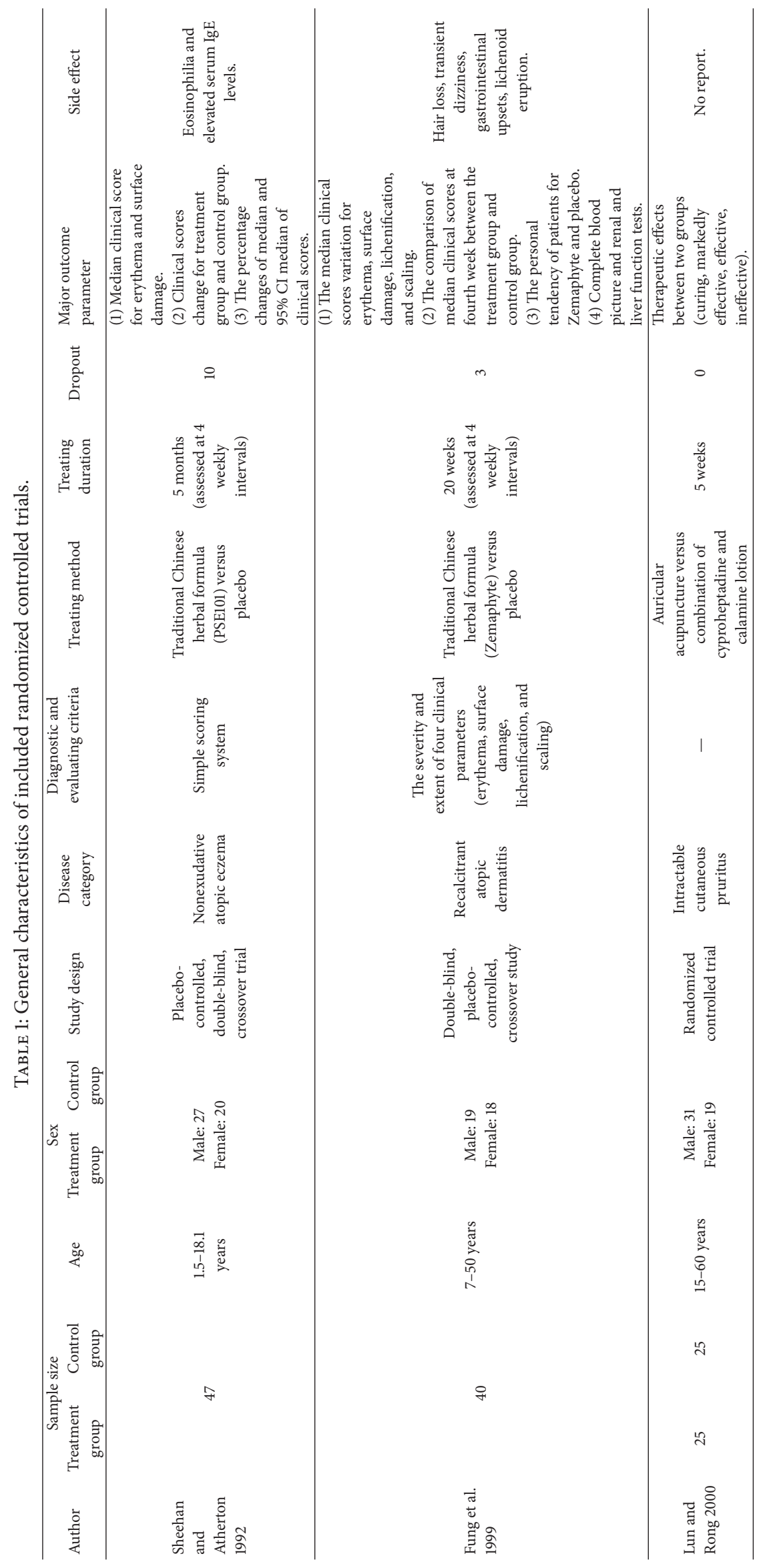




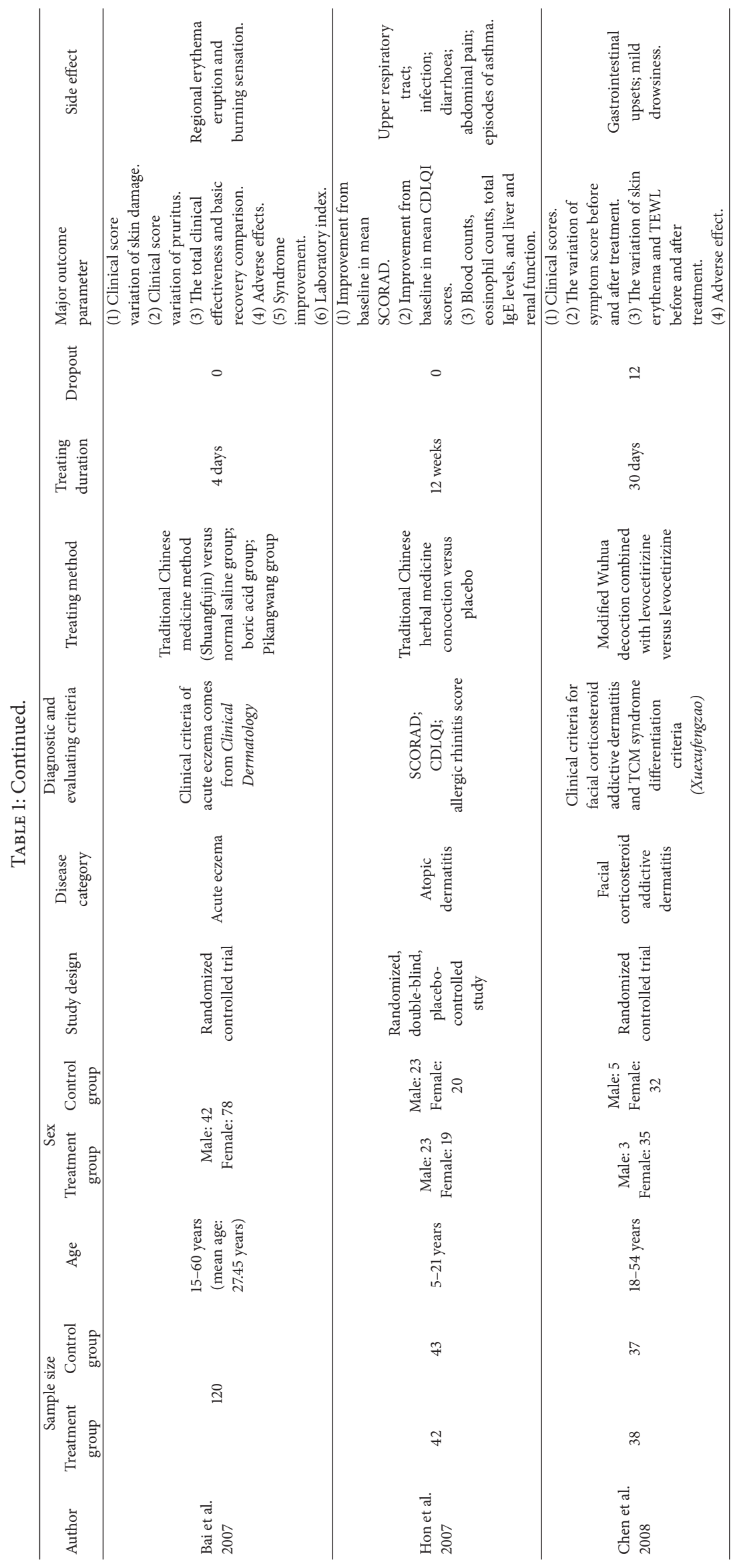




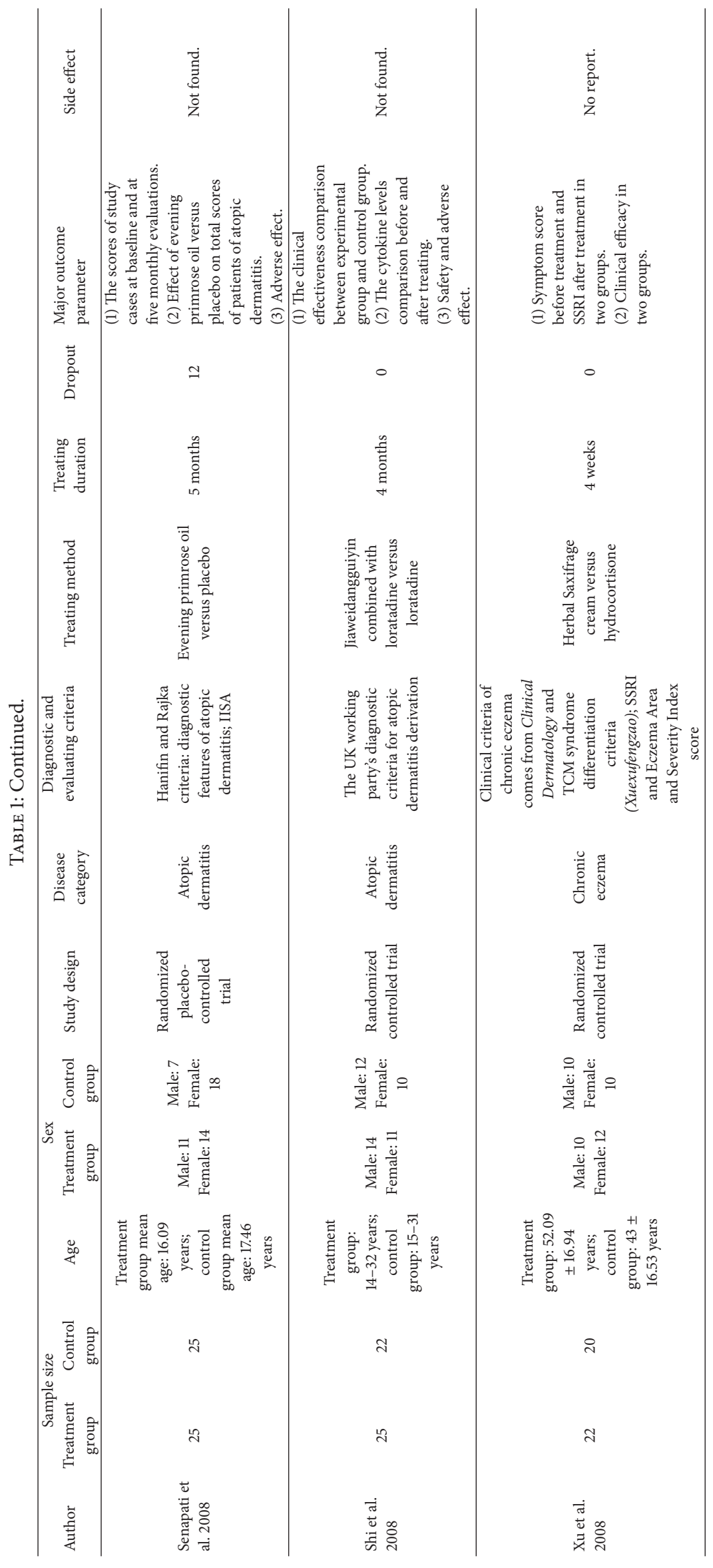




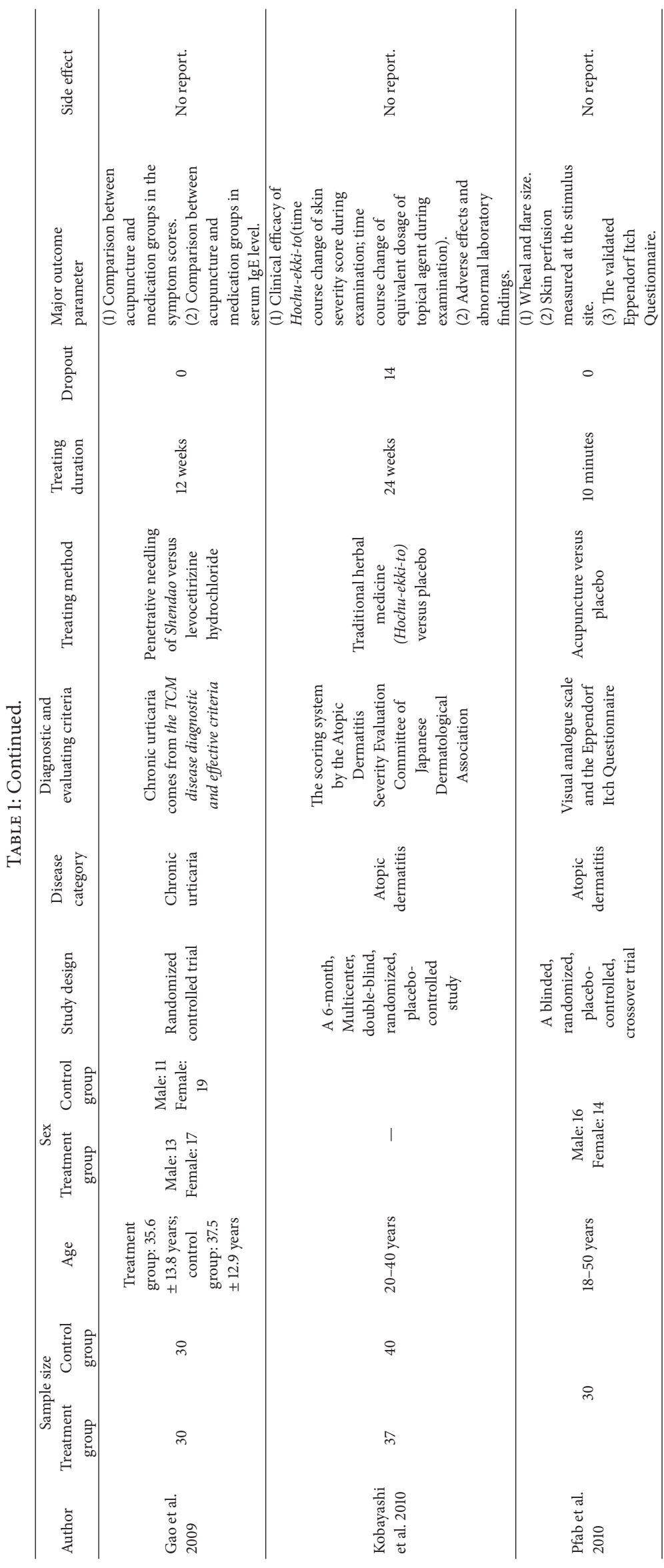




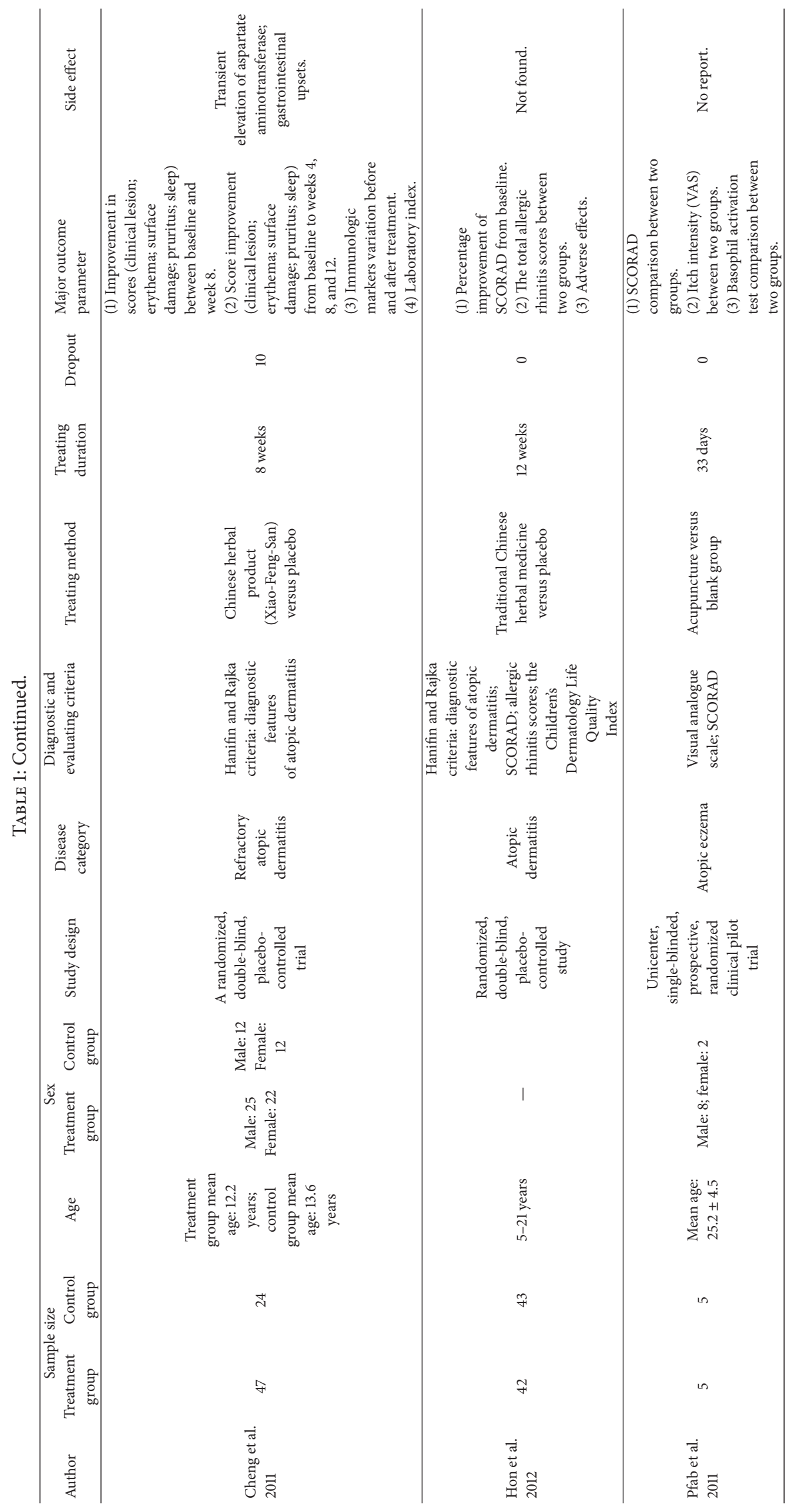




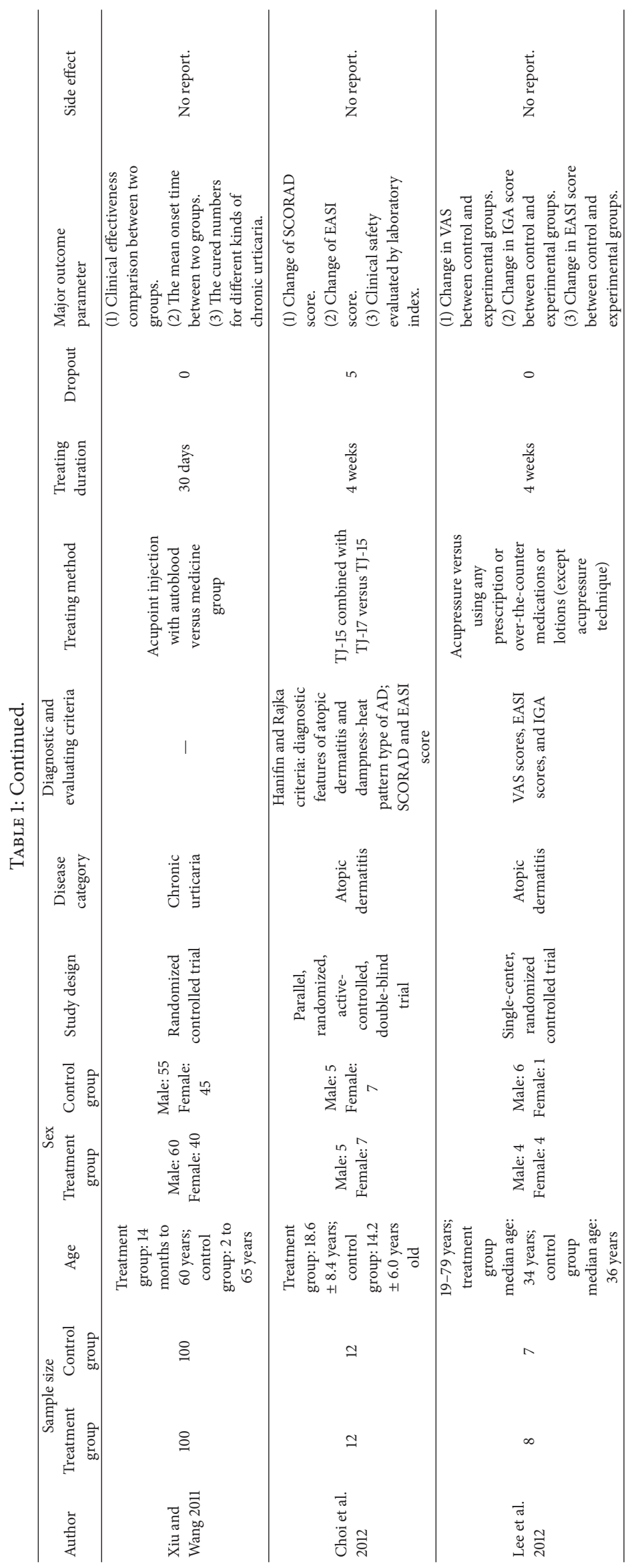




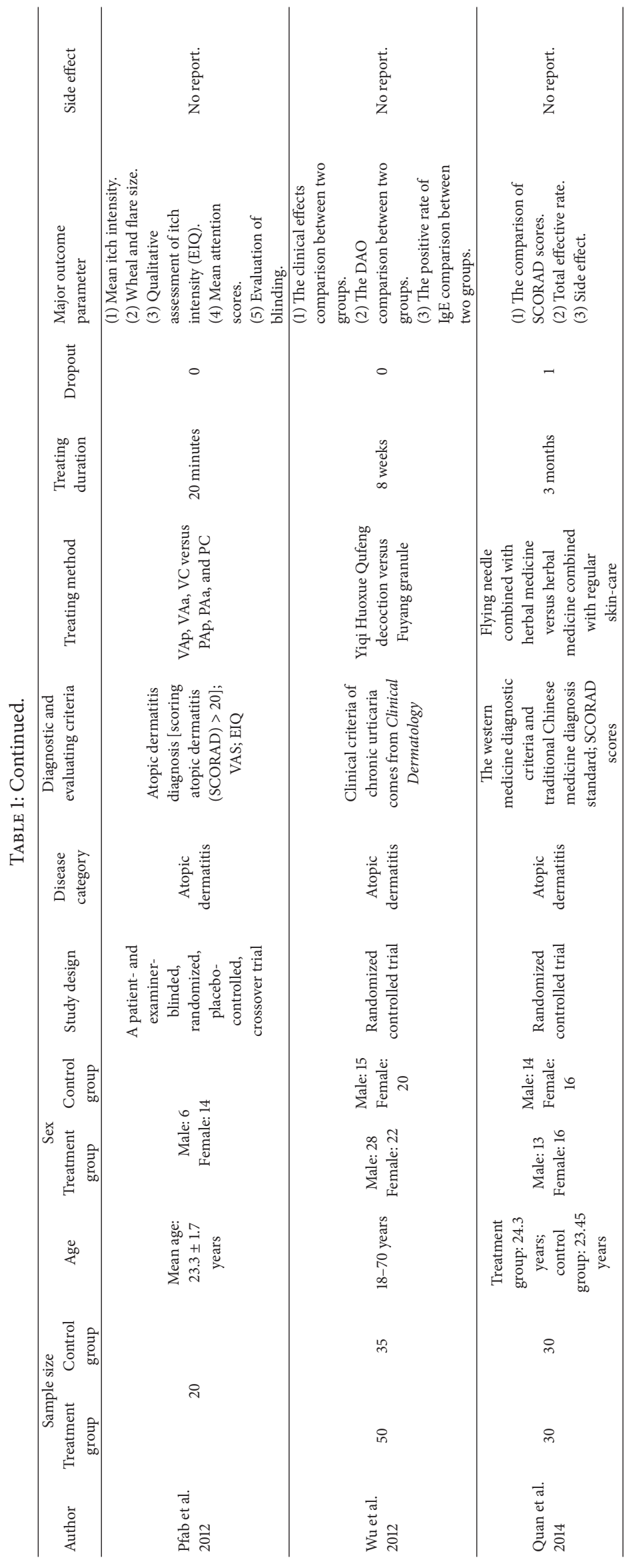




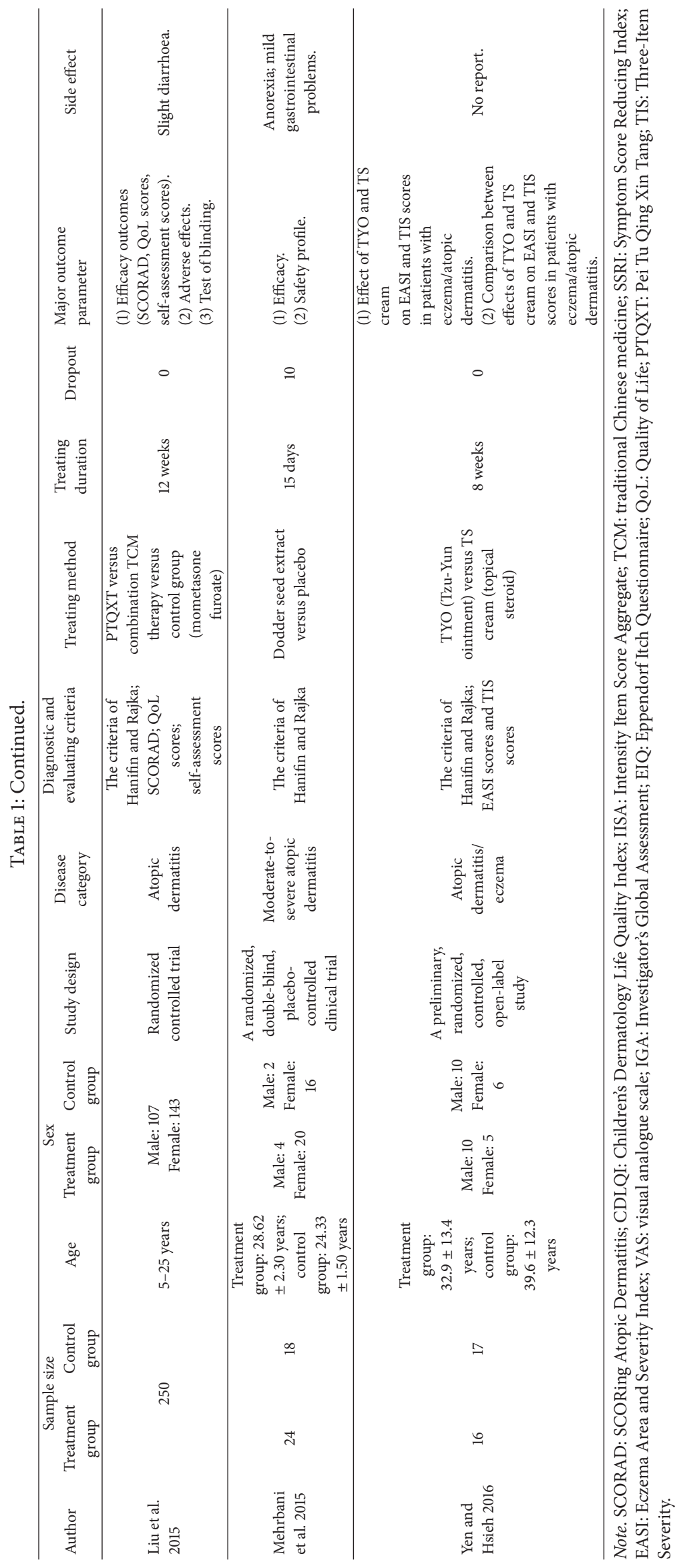


TABLE 2: The risk bias evaluation of articles.

\begin{tabular}{|c|c|c|c|c|c|c|c|}
\hline Article names & $\begin{array}{c}\text { Random collection } \\
\text { method }\end{array}$ & $\begin{array}{l}\text { Allocation } \\
\text { concealment }\end{array}$ & $\begin{array}{c}\text { The blinding } \\
\text { method }\end{array}$ & $\begin{array}{c}\text { Outcome } \\
\text { data integrity }\end{array}$ & $\begin{array}{l}\text { The outcome data } \\
\text { of selective report }\end{array}$ & $\begin{array}{c}\text { No other bias } \\
\text { sources }\end{array}$ & $\begin{array}{c}\text { The level of bias } \\
\text { risk }\end{array}$ \\
\hline $\begin{array}{l}\text { Sheehan and } \\
\text { Atherton } 1992\end{array}$ & $\mathrm{Y}$ & $\mathrm{Y}$ & $\mathrm{Y}$ & $\mathrm{Y}$ & $\mathrm{Y}$ & $\mathrm{U}$ & Low \\
\hline Fung et al. 1999 & $\mathrm{Y}$ & $\mathrm{Y}$ & $\mathrm{Y}$ & $\mathrm{Y}$ & $\mathrm{Y}$ & $\mathrm{U}$ & Low \\
\hline $\begin{array}{l}\text { Lun and Rong } \\
2000\end{array}$ & $\mathrm{Y}$ & $\mathrm{U}$ & $\mathrm{U}$ & $\mathrm{Y}$ & $\mathrm{Y}$ & $\mathrm{U}$ & Low \\
\hline Bai et al. 2007 & $\mathrm{Y}$ & $\mathrm{U}$ & U & $\mathrm{Y}$ & $\mathrm{Y}$ & U & Low \\
\hline Hon et al. 2007 & $\mathrm{Y}$ & $\mathrm{Y}$ & $\mathrm{Y}$ & $\mathrm{Y}$ & $\mathrm{Y}$ & U & Low \\
\hline Chen et al. 2008 & $\mathrm{Y}$ & $\mathrm{U}$ & $\mathrm{U}$ & $\mathrm{Y}$ & $\mathrm{Y}$ & $\mathrm{U}$ & Low \\
\hline $\begin{array}{l}\text { Senapati et al. } \\
2008\end{array}$ & $\mathrm{Y}$ & $\mathrm{Y}$ & $\mathrm{U}$ & $\mathrm{Y}$ & $\mathrm{Y}$ & $\mathrm{U}$ & Low \\
\hline Shi et al. 2008 & $\mathrm{Y}$ & $\mathrm{U}$ & $\mathrm{U}$ & $\mathrm{Y}$ & $\mathrm{Y}$ & $\mathrm{U}$ & Low \\
\hline Xu et al. 2008 & $\mathrm{Y}$ & $\mathrm{U}$ & $\mathrm{U}$ & $\mathrm{Y}$ & $\mathrm{Y}$ & $\mathrm{U}$ & Low \\
\hline Gao et al. 2009 & $\mathrm{Y}$ & U & U & $\mathrm{Y}$ & $\mathrm{N}$ & U & High \\
\hline $\begin{array}{l}\text { Kobayashi et al. } \\
2010\end{array}$ & $\mathrm{Y}$ & $\mathrm{Y}$ & $\mathrm{Y}$ & $\mathrm{Y}$ & $\mathrm{Y}$ & $\mathrm{U}$ & Low \\
\hline Pfab et al. 2010 & $\mathrm{Y}$ & $\mathrm{Y}$ & $\mathrm{Y}$ & $\mathrm{Y}$ & $\mathrm{Y}$ & $\mathrm{U}$ & Low \\
\hline Cheng et al. 2011 & $\mathrm{Y}$ & $\mathrm{U}$ & $\mathrm{U}$ & $\mathrm{Y}$ & $\mathrm{Y}$ & $\mathrm{U}$ & Low \\
\hline Hon et al. 2012 & $\mathrm{Y}$ & $\mathrm{Y}$ & $\mathrm{Y}$ & $\mathrm{Y}$ & $\mathrm{Y}$ & $\mathrm{U}$ & Low \\
\hline Pfab et al. 2011 & $\mathrm{Y}$ & $\mathrm{Y}$ & $\mathrm{Y}$ & $\mathrm{Y}$ & $\mathrm{Y}$ & $\mathrm{U}$ & Low \\
\hline $\begin{array}{l}\text { Xiu and Wang } \\
2011\end{array}$ & $\mathrm{Y}$ & $\mathrm{U}$ & $\mathrm{U}$ & $\mathrm{Y}$ & $\mathrm{Y}$ & $\mathrm{U}$ & Low \\
\hline Choi et al. 2012 & $\mathrm{Y}$ & $\mathrm{Y}$ & $\mathrm{Y}$ & $\mathrm{Y}$ & $\mathrm{Y}$ & $\mathrm{U}$ & Low \\
\hline Lee et al. 2012 & $\mathrm{Y}$ & $\mathrm{Y}$ & $\mathrm{U}$ & $\mathrm{Y}$ & $\mathrm{Y}$ & $\mathrm{N}$ & Low \\
\hline Pfab et al. 2012 & $\mathrm{Y}$ & $\mathrm{Y}$ & $\mathrm{Y}$ & $\mathrm{Y}$ & $\mathrm{Y}$ & $\mathrm{U}$ & Low \\
\hline Wu et al. 2012 & $\mathrm{Y}$ & $\mathrm{U}$ & $\mathrm{U}$ & Y & $\mathrm{Y}$ & $\mathrm{U}$ & Low \\
\hline Quan et al. 2014 & $\mathrm{Y}$ & $\mathrm{U}$ & U & $\mathrm{Y}$ & $\mathrm{Y}$ & $\mathrm{U}$ & Low \\
\hline Liu et al. 2015 & $\mathrm{Y}$ & $\mathrm{Y}$ & $\mathrm{Y}$ & $\mathrm{Y}$ & $\mathrm{Y}$ & $\mathrm{U}$ & Low \\
\hline $\begin{array}{l}\text { Mehrbani et al. } \\
2015\end{array}$ & $\mathrm{Y}$ & $\mathrm{Y}$ & $\mathrm{Y}$ & $\mathrm{Y}$ & $\mathrm{Y}$ & $\mathrm{U}$ & Low \\
\hline $\begin{array}{l}\text { Yen and Hsieh } \\
2016\end{array}$ & $\mathrm{Y}$ & U & $\mathrm{U}$ & $\mathrm{Y}$ & $\mathrm{Y}$ & U & Low \\
\hline
\end{tabular}

Note. Y refers to yes, $\mathrm{N}$ refers to no, and $\mathrm{U}$ refers to unknown.

eight included articles, five of them (62.5\%) [33, 35, 37, $38,49]$ performed traditional Chinese herbal medicine in the experimental group while three of them (37.5\%) [32, $45,50]$ performed acupuncture related therapies (acupoint injection with autoblood [32], flying needle [50], and auricular acupuncture [45]). Five studies were published before 2010 and three were published after 2010. The heterogeneity of clinical effectiveness was moderately high $\left(I^{2}=65 \%\right)$, so the random effects model was performed to calculate the combined data by Mantel-Haenszel test. The subgroup analysis was conducted based on the different treating methods (traditional Chinese medicine and related preparation, acupuncture, and related therapy) and publishing year of articles (before 2010, after 2010) to analyze the source of heterogeneity. Unfortunately, we still did not find the source of heterogeneity. The meta-analysis illustrated that the clinical effectiveness of $\mathrm{AD}$ for the experimental group which was performed by traditional Chinese medicines and relevant treatments was irrelevant to the control group $(\mathrm{RR}=1.10,95 \%$ $\mathrm{CI}=0.99$ to 1.21 , and $P=0.07>0.05$ ). There was no statistical difference for the result of clinical effectiveness.

3.2.2. SCORAD Amelioration. Figure 5 was the forest plot which illustrated the SCORing Atopic Dermatitis (SCORAD) amelioration after traditional Chinese medicines and relevant treatments for experimental groups and western medicine or placebo treatments for control groups. Four articles including 173 patients were collected and analyzed in the forest plot of meta-analysis [43, 44, 46, 50]. Standard Mean Difference (Std. MD) was conducted as a combined statistics for the cause of the obvious difference of standard deviation (SD) in the same articles' SCORAD result. Of the included studies, two $(50 \%)$ conducted traditional Chinese herbal medicine as experimental method $[43,46]$ and others (50\%) conducted 


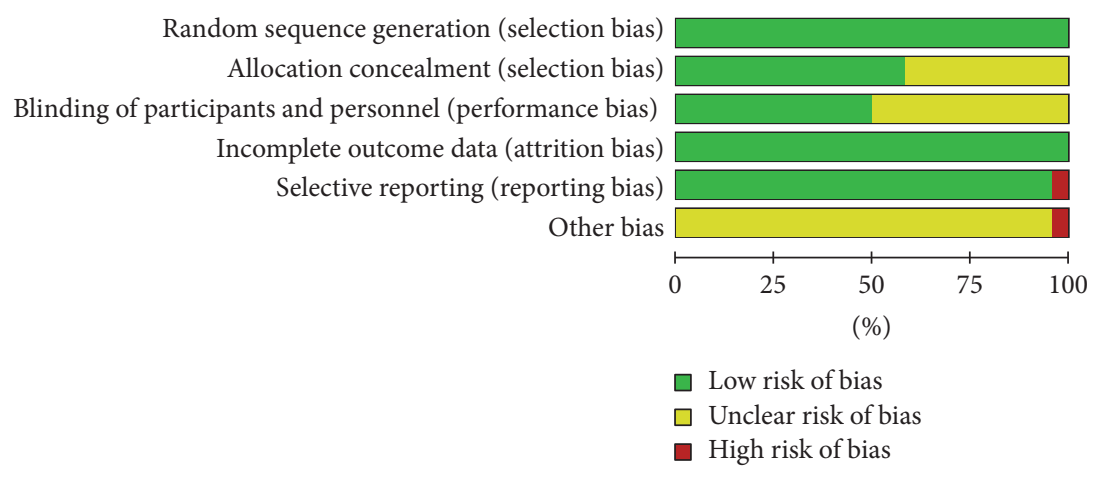

FIgURE 2: The risk of bias graph.

acupuncture [44] and flying needle [50]. The heterogeneity was so high $\left(I^{2}=86 \%\right)$ that the random effects model was conducted to calculate the combined data by inverse variance (IV) approach. The subgroup analysis was performed based on the treating methods (traditional Chinese medicine and related preparation, acupuncture and related therapy) to find the source of heterogeneity. However, the result still could not provide the certain conclusion. The meta-analysis showed that the SCORAD amelioration for the experimental group and the control group was irrelevant (Std. MD $=0.89,95 \% \mathrm{CI}$ $=-0.24$ to 2.02 , and $P=0.12>0.05$ ). The result of SCORAD amelioration had no statistical difference.

3.2.3. EASI Amelioration. Figure 6 showed the Eczema Area and Severity Index (EASI) amelioration after traditional Chinese medicines and relevant treatments for experimental groups and western medicine or placebo treatments for control groups. Only 2 studies which incorporated 50 participants were analyzed in meta-analysis $[46,53]$ and Mean Difference (MD) was conducted as a combined statistics. Both the included trials chose traditional Chinese herbal medicine in the experimental group for $\mathrm{AD}$ therapy and were published in recent years. There was no heterogeneity $\left(I^{2}\right.$ $=0 \%)$ in the meta-analysis, so the fixed-effects model was conducted to calculate the combined data by inverse variance (IV) approach. The meta-analysis revealed that traditional Chinese herbal medicine was superior to western medicine for EASI amelioration in $\mathrm{AD}$ (Std. $\mathrm{MD}=3.22,95 \% \mathrm{CI}=$ 0.41 to 6.03 , and $P=0.02<0.05)$. The result had statistical difference.

3.2.4. SSRI Amelioration. Figure 7 illustrated the Symptom Score Reducing Index (SSRI) amelioration after traditional Chinese medicines or related treatments for experimental groups and western medicine or placebo treatments for control groups. Only 2 appropriate articles including 105 patients were collected and analyzed in meta-analysis $[35,38]$. Standard Mean Difference (Std. MD) was conducted as a combined statistics for the cause of the obvious difference of standard deviation (SD) of the same article in SSRI result. Two included articles both used traditional Chinese herbal medicines in the experimental group for $\mathrm{AD}$ treatment. We found that the heterogeneity of included studies was obvious $\left(I^{2}=76 \%\right)$ maybe because of the variation of Chinese medicine ingredients between two trials and measurement time. The random effects model was conducted to calculate the combined data by inverse variance (IV) approach. The meta-analysis showed that the SSRI amelioration for the experimental group and the control group was irrelevant (Std. $\mathrm{MD}=-0.36,95 \% \mathrm{CI}=-1.16$ to 0.45 , and $P=0.39>0.05)$. The result of SSRI amelioration had no statistical difference.

3.2.5. Funnel Plot Characteristics. The funnel plot (Figure 8) was drawn by reviewer (Zhao-feng Shi) based on pooled odds ratio (OR) as the midpoint. The publication bias of clinical effectiveness in included studies was evaluated by comparing the symmetry of the funnel plot. The symmetry of funnel plot was assessed by two reviewers' cooperation (Juan Xie and Yi-quan Yan) in the visual aspect and both the reviewers considered that this image was symmetrical, which means the clinical effectiveness did not have the publication bias. We also conducted Egger's test and Begg's test to confirm whether the publication did exist. The calculating result of Egger's $(t=1.36, P=0.247)$ and Begg's test $(z=1.88$, $P=0.06)$ and images indicated that the publication bias did not exist [54] (Figure 9).

\section{Discussion}

4.1. Summary of the Main Evidence. This systematic review and meta-analysis have shown the clinical effectiveness of traditional Chinese medicine and related treatment and the amelioration of related evaluating criteria for atopic dermatitis (AD) therapy by collecting 24 high quality articles from 8 main international electronic databases. The evidence-based rules of traditional Chinese medicine and related treatment for $\mathrm{AD}$ have been conducted by this systematic review and meta-analysis. This study has four obvious advantages: (a) articles having good quality based on the Cochrane Collaboration's tools for the risk of bias assessment were included ensuring that the results trustworthy; (b) the articles' quality was evaluated by three reviewers' cooperation (Zhao-feng Shi, Juan Xie and Yi-quan Yan); (c) the subgroup analysis was well performed to find the source of heterogeneity; (d) the author was contacted by our reviewers if an appropriate study cannot be acquired as full-text; (e) the funnel plot, Egger's test, 


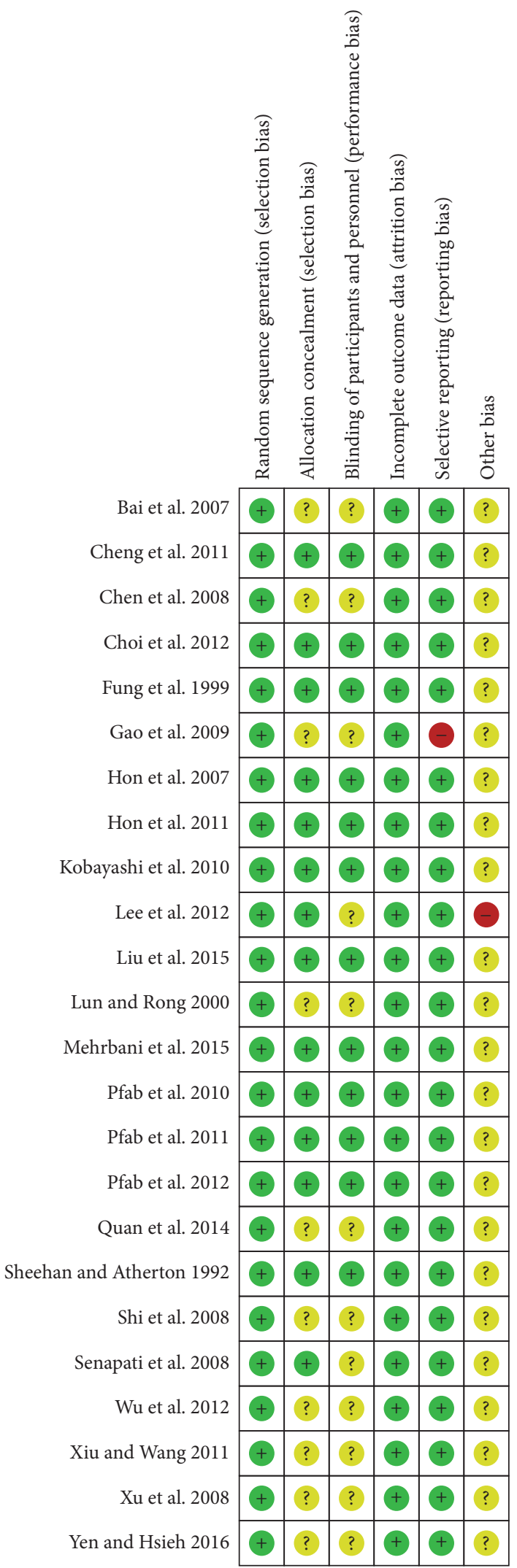

FIGURE 3: The risk of bias summary. 


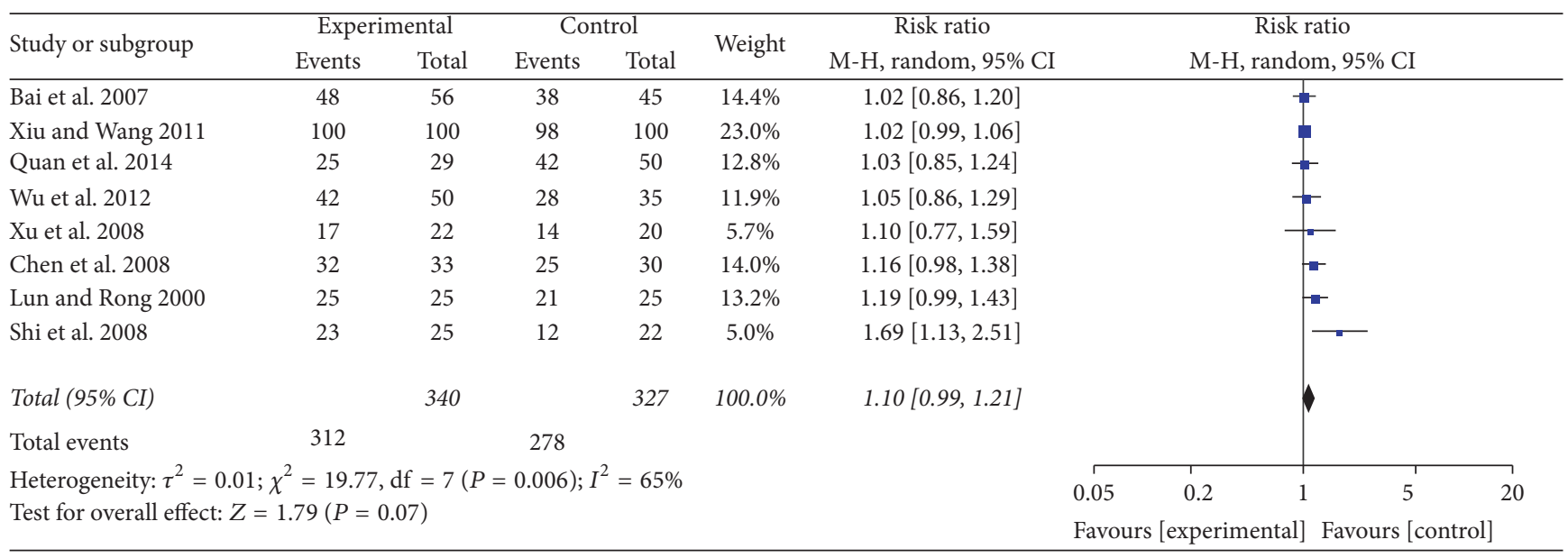

FIGURE 4: The forest plot of clinical effectiveness for traditional Chinese medicine and relevant treatment versus placebo or western medicine in $\mathrm{AD}$ treatment (M-H: Mantel-Haenszel estimates; CI: confidence interval).

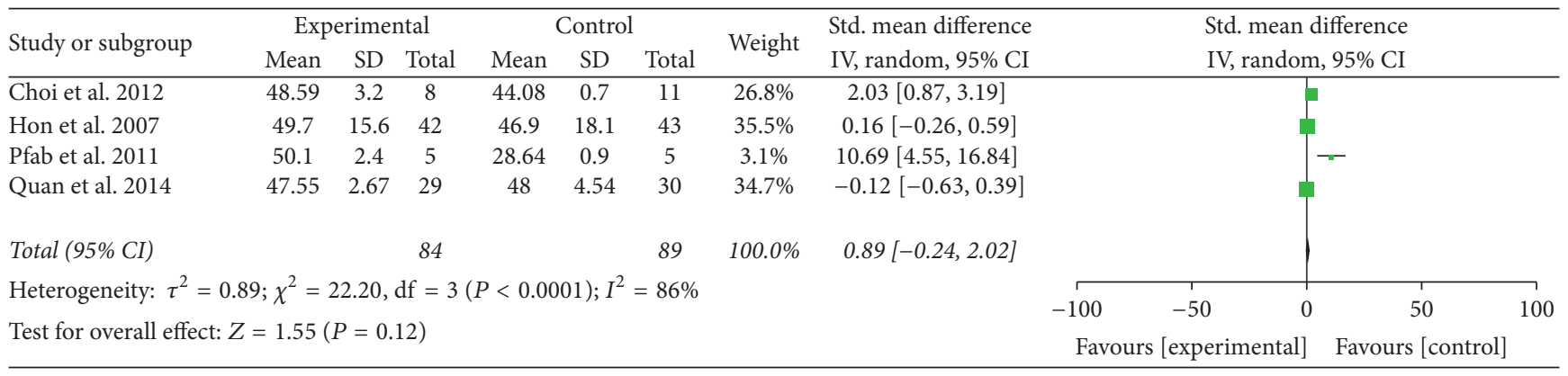

FIGURE 5: The forest plot of SCORAD amelioration for traditional Chinese medicine and relevant treatment versus placebo or western medicine in $\mathrm{AD}$ treatment (I-V: inverse variance; $\mathrm{CI}$ : confidence interval).

\begin{tabular}{|c|c|c|c|c|c|c|c|c|c|c|c|c|c|}
\hline \multirow{2}{*}{ Study or subgroup } & \multicolumn{3}{|c|}{ Experimental } & \multicolumn{3}{|c|}{ Control } & \multirow{2}{*}{ Weight } & \multirow{2}{*}{$\begin{array}{l}\text { Mean difference } \\
\text { IV, fixed, 95\% CI }\end{array}$} & \multirow{2}{*}{\multicolumn{5}{|c|}{$\begin{array}{l}\text { Mean difference } \\
\text { IV, fixed, 95\% CI }\end{array}$}} \\
\hline & \multirow{2}{*}{$\frac{\text { Mean }}{20.67}$} & \multirow{2}{*}{$\begin{array}{l}\text { SD } \\
7.9\end{array}$} & \multirow{2}{*}{$\begin{array}{c}\text { Total } \\
8\end{array}$} & \multirow{2}{*}{$\begin{array}{l}\text { Mean } \\
18.56\end{array}$} & \multirow{2}{*}{$\begin{array}{l}\text { SD } \\
3.9\end{array}$} & Total & & & & & & & \\
\hline Choi et al. 2012 & & & & & & 11 & $22.4 \%$ & $2.11[-3.83,8.05]$ & & & - & & \\
\hline Yen and Hsieh 2016 & 6.66 & 6.06 & 16 & 3.12 & 2.32 & 15 & $77.6 \%$ & $3.54[0.35,6.73]$ & & & & & \\
\hline Total (95\% CI) & & & 24 & & & 26 & $100.0 \%$ & $3.22[0.41,6.03]$ & & & $\gamma$ & & \\
\hline Heterogeneity: $\chi^{2}=$ & $\mathrm{df}=1$ & $P=0$ & $.68) ; I^{2}$ & $=0 \%$ & & & & & -100 & -50 & 0 & 50 & 100 \\
\hline Test for overall effect & 2.24 & $=0.0$ & & & & & & & $\mathrm{Fa}$ & [expe & & Favours $[\mathrm{cc}$ & \\
\hline
\end{tabular}

FIGURE 6: The forest plot of EASI amelioration for traditional Chinese medicine and relevant treatment versus placebo or western medicine in $\mathrm{AD}$ treatment (I-V: inverse variance; $\mathrm{CI}$ : confidence interval).

\begin{tabular}{|c|c|c|c|c|c|c|c|c|c|c|c|c|c|}
\hline \multirow{2}{*}{ Study or subgroup } & \multicolumn{3}{|c|}{ Experimental } & \multicolumn{3}{|c|}{ Control } & \multirow{2}{*}{ Weight } & Std. mean difference & & \multirow{2}{*}{\multicolumn{3}{|c|}{$\begin{array}{l}\text { Std. mean difference } \\
\text { IV, random, 95\% CI }\end{array}$}} & \\
\hline & Mean & SD & Total & Mean & $\mathrm{SD}$ & Total & & IV, random, 95\% CI & & & & & \\
\hline Chen et al. 2008 & 10.38 & 0.48 & 33 & 10.68 & 0.27 & 30 & $52.0 \%$ & $-0.75[-1.26,-0.24]$ & & & & & \\
\hline Xu et al. 2008 & 108.54 & 38.03 & 22 & 105.89 & 35.27 & 20 & $48.0 \%$ & $0.07[-0.53,0.68]$ & & & & & \\
\hline \multicolumn{3}{|l|}{ Total $(95 \% \mathrm{CI})$} & 55 & & & 50 & $100.0 \%$ & $-0.36[-1.16,0.45]$ & & & & & \\
\hline \multicolumn{9}{|c|}{ Heterogeneity: $\tau^{2}=0.26 ; \chi^{2}=4.12, \mathrm{df}=1(P=0.04) ; I^{2}=76 \%$} & -100 & -50 & 0 & 50 & 100 \\
\hline \multicolumn{9}{|c|}{ Test for overall effect: $Z=0.87(P=0.39)$} & Fav & [exper & & $\mathrm{rs}[\mathrm{co}$ & \\
\hline
\end{tabular}

FIGURE 7: The forest plot of SSRI amelioration for traditional Chinese medicine and relevant treatment versus placebo or western medicine in $\mathrm{AD}$ treatment (I-V: inverse variance; $\mathrm{CI}$ : confidence interval). 


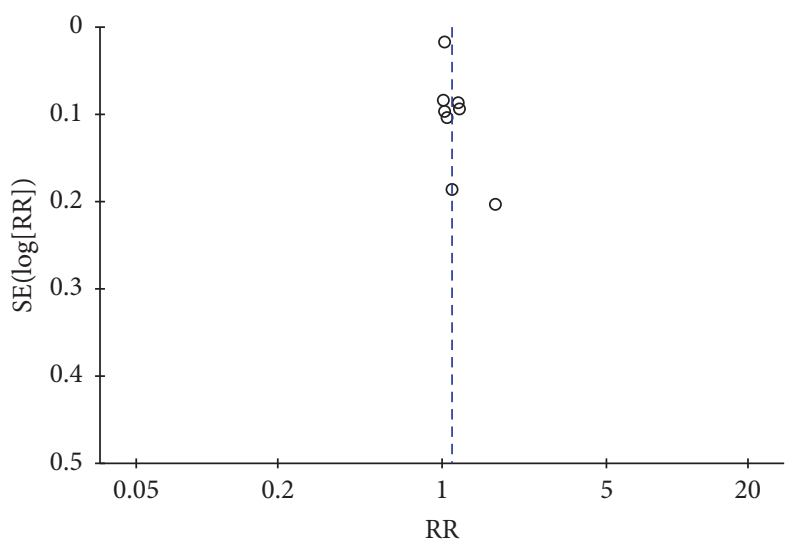

Figure 8: The funnel plot of clinical effectiveness.
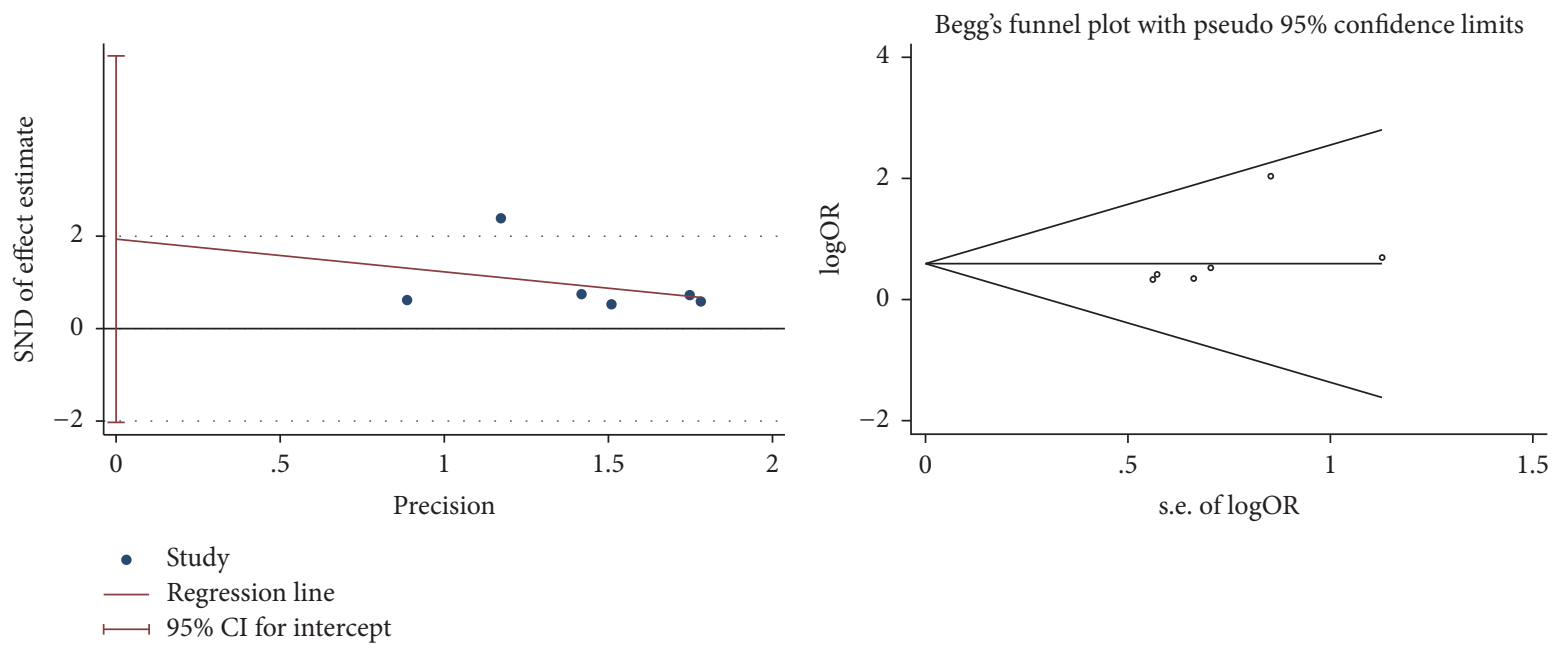

FIGURE 9: Egger's test and Begg's test of clinical effectiveness.

and Begg's test were conducted to evaluate the publication bias of articles' clinical effectiveness.

The result of the clinical effectiveness of traditional Chinese medicines and relevant treatments for atopic dermatitis (AD) therapy in meta-analysis showed that the experimental group (traditional Chinese medicine and relevant treatment) was irrelevant to the control group (placebo or western medicine). The subgroup analysis did not reveal the source of heterogeneity. The clinical evaluating criteria amelioration of SCORAD and SSRI for the traditional Chinese medicines and relevant treatments of $\mathrm{AD}$ provided the same conclusion as the clinical effectiveness. However, the result of EASI in metaanalysis illustrated that the experimental group (traditional Chinese medicine and relevant treatment) was superior to the control group (placebo or western medicine). Egger's and Begg's test and funnel plot did not reveal the publication bias for clinical effectiveness. In a word, under this circumstance, we could not give the firm conclusion on the effectiveness of traditional Chinese medicines and relevant treatments for $\mathrm{AD}$ except that we can include more relevant articles and credible results in the future meta-analysis.
4.2. The AD Adjunctive Therapy for Recommendations. Atopic dermatitis (AD) was recognized as a common inflammatory skin disease nowadays that bring much burden to humankind around the world, with the reported rate as high as $30 \%$ of children and $10 \%$ of adults [1]. Despite the obvious adverse effects (deranged metabolism, growth suppression, increased susceptibility to infection, and suppression of the hypothalamic-pituitary-adrenal axis) [55, 56], western medicines that included skin emollients, corticosteroids, antihistamines, and immunomodulation agents still have been put forward as $\mathrm{AD}$ standard therapy for a long time. Under the characteristics of a chronic course and repeated attack of $\mathrm{AD}$, clinical physicians tried their best to find appropriate adjunctive treatments for better clinical control of AD symptoms. Traditional Chinese medicines and related treatments are popular examples of $\mathrm{AD}$ adjunctive therapy, which could be grouped in Complementary and Alternative Medical (CAM) treatments category.

In many Asian countries, such as China, Japan, South Korea, India, and Iran, traditional Chinese medicine (TCM) had been applied on clinical areas of AD for its outstanding 
efficacy and safety. TCM may have the ability to downregulate cells that associated with $\mathrm{AD}$ through antioxidant activities [57]. In addition to that, TCM may affect the structure of the developing dendritic cells (DCs) through losing their typical dendritic morphology and decreasing their expression of CD1a as well as the low affinity IgE receptor CD23 [58]. A China TCM Expert Consensus of AD was published in 2013, separating AD as four main syndromes based on theory of TCM: firstly, the brimming heat of heart and spleen syndrome, conducting the Chinese herbal prescription named Sanxindaochiyin; secondly, the heat of heart and spleen deficiency syndrome, conducting Qinxinpeitufang; thirdly, the spleen deficiency and dampness retention syndrome, performing Xiaoerhuashitang; fourthly, the syndrome of wind and dryness due to blood deficiency, conducting Dangguiyinzi [59]. However, there was still lack of modern randomized controlled trials to cautiously evaluate the TCM treatment of $\mathrm{AD}$ and the pharmacological mechanism of TCM for AD has been difficult to explain. Acupuncture and the relevant therapies (such as flying needle, auricular needle, and electroacupuncture) have been shown to be practical in patients with $\mathrm{AD}$ that may be due to the antipruritic effect of kappa-opioid receptor activated by high-frequency stimulation [60]. However, since many of them lack scientific verification, they should be performed under the supervision of physicians [12].

4.3. Limitation. This systematic review and meta-analysis had several potential limitations restricting the clinical application for AD: (a) Included studies are smaller than we expected although reviewers restricted the electric database numbers for high quality articles. (b) The number of participants in some included studies is small: Pfab. F only included 10 patients in their studies and Lee K.C.'s article only contains 15 patients $[44,47]$. We consider that the limited participant numbers may be insufficient to evaluate the efficiency and safety of $\mathrm{AD}$ therapy. (c) The heterogeneity of included studies is obvious although reviewers conducted strictly study selection, data extraction, and quality analysis. And the subgroup analysis of studies also could not clearly reveal the source of heterogeneity. We estimate that the heterogeneity may come from the sample size, medicine application and dose, and publication years, as well as treating duration. We are required to understand that the random effects model was performed to pool data which cannot give exact and stable conclusion in this situation. (d) The traditional Chinese medicines and related treatments are diversified in the included articles: some studies used traditional Chinese herbal medicines and some studies performed acupuncture and related treatments. Also, therapy in control group could not reach a consensus as a uniform method.

\section{Conclusion}

In conclusion, this systematic review and meta-analysis did not provide the practical and beneficial results of traditional Chinese medicine and related treatment for atopic dermatitis (AD) therapy. Although the Eczema Area and Severity Index (EASI) amelioration in the meta-analysis showed a statistical difference, the clinical meaning was restricted by the shortage of included articles. So this aspect conclusion needs to be confirmed by more clinical studies in the future. As for evaluating aspects of clinical effectiveness, SCORAD amelioration, and SSRI amelioration, we did not find any firm outcome for the superiority of traditional Chinese medicine and related treatment in AD therapy. Further and deeper standard, multicenter, double-blind randomized clinical trials (RCTs) of traditional Chinese medicine and related treatment for $\mathrm{AD}$ were urgent to be conducted for more clinical evidences providing in the future. The underlying pharmacological mechanism of traditional Chinese medicine and related treatment needs to be researched and revealed for its future application of $\mathrm{AD}$ therapy.

\section{Conflicts of Interest}

The authors declare that there are no conflicts of interest.

\section{Authors' Contributions}

Zhao-feng Shi, Tie-bing Song, and Juan Xie have contributed equally to this work. The databases were searched and data were extracted by Zhao-feng Shi, Tie-bing Song, Juan Xie, and Yi-quan Yan. The statistical analysis was conducted by Zhao-feng Shi and modified by Yong-ping Du. Study tables and figures were conducted by Zhao-feng Shi. The basic knowledge of traditional Chinese medicine (TCM) was guided by Yong-ping Du.

\section{Acknowledgments}

This article was supported by the Youth Science Fund Project of China National Natural Science Foundation (no. 81403292), the Natural Science Basic Study Project of Shaanxi Province (no. 2015JQ8290), and the Boosting Project of Xijing Hospital (no. XJZT13M18).

\section{References}

[1] T. Bieber, "Atopic dermatitis," The New England Journal of Medicine, vol. 358, no. 14, pp. 1483-1494, 2008.

[2] F. Xu, S. Yan, F. Li et al., "Prevalence of childhood atopic dermatitis: an urban and rural community-based study in shanghai, China," PLoS ONE, vol. 7, no. 5, article e36174, 2012.

[3] A. J. Mancini, K. Kaulback, and S. L. Chamlin, "The socioeconomic impact of atopic dermatitis in the United States: a systematic review," Pediatric Dermatology, vol. 25, no. 1, pp. 1-6, 2008.

[4] T. Hirota, A. Takahashi, M. Kubo et al., "Genome-wide association study identifies eight new susceptibility loci for atopic dermatitis in the Japanese population," Nature Genetics, vol. 44, no. 11, pp. 1222-1226, 2012.

[5] H. Murota, M. Izumi, M. I. A. Abd El-Latif et al., "Artemin causes hypersensitivity to warm sensation, mimicking warmthprovoked pruritus in atopic dermatitis," Journal of Allergy and Clinical Immunology, vol. 130, no. 3, pp. 671-682, 2012.

[6] C. Vestergaard, K. Bang, B. Gesser, H. Yoneyama, K. Matsushima, and C. G. Larsen, "A Th2 chemokine, TARC, produced by keratinocytes may recruit CLA+CCR4+ lymphocytes into 
lesional atopic dermatitis skin," Journal of Investigative Dermatology, vol. 115, no. 4, pp. 640-646, 2000.

[7] J. Hanifin and G. Rajka, "Diagnostic features of atopic eczema," Journal of Applied Bacteriology, vol. 72, no. 4, pp. 322-326, 1980.

[8] The skin venereology branch of Chinese medical association immune group, Atopic dermatitis collaborative and research center, "China atopic dermatitis guidelines (2014 version)," Chinese Journal of Dermatology, vol.47, no.7, pp.511-514, 2014.

[9] H. C. Williams, P. G. Burney, R. J. Hay et al., “The U. K. working party's diagnostic criteria for atopic dermatitis I derivation of a minimum set of discriminators for atopic dermatitis," British Journal of Dermatology, vol. 131, no. 3, pp. 383-396, 1994.

[10] A. P. Oranje, J.-F. Stalder, A. Taïeb, C. Tasset, and M. De Longueville, "Scoring of atopic dermatitis by SCORAD using a training atlas by investigators from different disciplines," Pediatric Allergy and Immunology, vol. 8, no. 1, pp. 28-34, 1997.

[11] J. M. Hanifin, M. Thurston, M. Omoto, R. Cherill, S. J. Tofte, and M. Graeber, "The eczema area and severity index (EASI): assessment of reliability in atopic dermatitis," Experimental Dermatology, vol. 10, no. 1, pp. 11-18, 2001.

[12] I. Katayama, Y. Kohno, K. Akiyama et al., "Japanese guideline for atopic dermatitis 2014," Allergology International, vol. 63, no. 3, pp. 377-398, 2014.

[13] C. Hoare, A. Li Wan Po, and H. Williams, "Systematic review of treatments for atopic eczema," Health Technology Assessment, vol. 117, no. 3, pp. 758-758, 2001.

[14] C. Ellis, T. Luger, D. Abeck et al., "International consensus conference on atopic dermatitis II (ICCAD II): clinical update and current treatment strategies," British Journal of Dermatology, vol. 148, suppl. 63, pp. 3-10, 2003.

[15] W. Abramovits and A. Perlmutter, "Steroids versus other immune modulators in the management of allergic dermatoses," Current Opinion in Allergy and Clinical Immunology, vol. 6, no. 5, pp. 345-354, 2006.

[16] Z. Draelos, A. Nayak, D. Pariser et al., "Pharmacokinetics of topical calcineurin inhibitors in adult atopic dermatitis: a randomized, investigator-blind comparison," Journal of the American Academy of Dermatology, vol. 53, no. 4, pp. 602-609, 2005.

[17] N. A. Soter, A. B. Fleischer Jr., G. F. Webster, E. Monroe, and I. Lawrence, "Tacrolimus ointment for the treatment of atopic dermatitis in adult patients: part II, safety," Journal of the American Academy of Dermatology, vol. 44, no. 1, pp. S39-S46, 2001.

[18] M. K. Bedi and P. D. Shenefelt, "Herbal therapy in dermatology," Archives of Dermatology, vol. 138, no. 2, pp. 232-242, 2002.

[19] W. Zhang, T. Leonard, F. Bath-Hextall et al., "Chinese herbal medicine for atopic eczema," Cochrane Database of Systematic Reviews, vol. 4, article CD002291, 2004.

[20] S. Gu, A. W. H. Yang, C. C. L. Xue et al., "Chinese herbal medicine for atopic eczema," The Cochrane Database of Systematic Reviews, vol. 9, article CD008642, 2013.

[21] N.-K. Kim, D.-H. Lee, H.-S. Seo et al., "Hwangryunhaedoktang in adult patients with Atopic Dermatitis: A randomised, doubleblind, placebo-controlled, two-centre trial-study protocol," BMC Complementary and Alternative Medicine, vol. 11, article 68, 2011.

[22] D. Moher, A. Liberati, J. Tetzlaff, and D. G. Altman, "Preferred reporting items for systematic reviews and meta-analyses: the PRISMA statement," British Medical Journal, vol. 339, article b2535, 2009.
[23] M. S. Salek, S. Jung, L. A. Brincat-Ruffini et al., "Clinical experience and psychometric properties of the children's dermatology life quality index (CDLQI), 1995-2012," British Journal of Dermatology, vol. 169, no. 4, pp. 734-759, 2013.

[24] J. P. T. Higgins and S. Green The Cochrane Collaboration, 2011, http://handbook.cochrane.org/.

[25] J. P. T. Higgins, S. G. Thompson, J. J. Deeks, and D. G. Altman, "Measuring inconsistency in meta-analyses," British Medical Journal, vol. 327, no. 7414, pp. 557-560, 2003.

[26] A. Donald and A. Donner, "Adjustments to the MantelHaenszel chi-square statistic and odds ratio variance estimator when the data are clustered," Statistics in Medicine, vol. 6, no. 4, pp. 491-499, 1987.

[27] D. Bohning, U. Malzahn, E. Dietz et al., "Some general points in estimating heterogeneity variance with the DerSimonian-Laird estimator," Biostatistics, vol. 3, no. 4, pp. 445-457, 2002.

[28] J. A. C. Sterne and M. Egger, "Funnel plots for detecting bias in meta-analysis: guidelines on choice of axis," Journal of Clinical Epidemiology, vol. 54, no. 10, pp. 1046-1055, 2001.

[29] M. Egger, G. D. Smith, M. Schneider, and C. Minder, "Bias in meta-analysis detected by a simple, graphical test," British Medical Journal, vol. 315, no. 7109, pp. 629-634, 1997.

[30] M. P. Sheehan and D. J. Atherton, "A controlled trial of traditional Chinese medicinal plants in widespread non-exudative atopic eczema," British Journal of Dermatology, vol. 126, no. 2, pp. 179-184, 1992.

[31] A. Y. P. Fung, P. C. N. Look, L.-Y. Chong, P. P. H. But, and E. Wong, "A controlled trial of traditional Chinese herbal medicine in Chinese patients with recalcitrant atopic dermatitis," International Journal of Dermatology, vol. 38, no. 5, pp. 387392, 1999.

[32] X. Lun and L. Rong, "Twenty-five cases of intractable cutaneous pruritus treated by auricular acupuncture," Journal of Traditional Chinese Medicine, vol. 20, no. 4, pp. 287-288, 2000.

[33] Y. P. Bai, D. Q. Yang, and Y. M. Wang, "Clinical study on treatment of acute eczema by Shuangfujin," Chinese Journal of Integrative Medicine, vol. 27, no. 1, pp. 72-75, 2007.

[34] K. L. E. Hon, T. F. Leung, P. C. Ng et al., "Efficacy and tolerability of a Chinese herbal medicine concoction for treatment of atopic dermatitis: a randomized, double-blind, placebo-controlled study," British Journal of Dermatology, vol. 157, no. 2, pp. 357363, 2007.

[35] S. Y. Chen, W. M. Song, and X. H. Du, "Effect of modified wuhua decoction on skin barrier function in facial corticosteroid addictive dermatitis patients," Chinese Journal of Integrative Medicine, vol. 25, no. 8, pp. 410-413, 2008.

[36] S. Senapati, S. Banerjee, and D. N. Gangopadhyay, "Evening primrose oil is effective in atopic dermatitis: a randomized placebo-controlled trial," Indian Journal of Dermatology, Venereology and Leprology, vol. 74, no. 5, pp. 447-452, 2008.

[37] Y. J. Shi, C. M. Zhang, and D. M. Ma, "Clinical study on treatment of atopic dermatitis by integrated traditional Chinese and Western medicine," Chinese Journal of Integrative Medicine, vol. 28, no. 8, pp. 686-688, 2008.

[38] R. Xu, F.-L. Li, L.-L. Zhang, X. Song, J.-L. Zhu, and B. Li, "Herba Saxifragae cream in treatment of chronic eczema: a randomized controlled trial," Journal of Chinese Integrative Medicine, vol. 6, no. 12, pp. 1246-1249, 2008.

[39] H. Gao, X. Z. Li, W. W. Ye et al., "Influence of penetrative needling of Shendao (GV 11) on the symptom score and serum IgE content in chronic urticaria patients," Acupuncture Research, vol. 34, no. 4, pp. 272-275, 2009. 
[40] H. Kobayashi, M. Ishii, S. Takeuchi et al., "Efficacy and safety of a traditional herbal medicine, hochu-ekki-to in the longterm management of Kikyo (Delicate Constitution) patients with atopic dermatitis: a 6-month, multicenter, double-blind, randomized, placebo-controlled study," Evidence-based Complementary and Alternative Medicine, vol. 7, no. 3, pp. 367-373, 2010.

[41] F. Pfab, J. Huss-Marp, A. Gatti et al., "Influence of acupuncture on type i hypersensitivity itch and the wheal and flare response in adults with atopic eczema-a blinded, randomized, placebocontrolled, crossover trial," Allergy, vol. 65, no. 7, pp. 903-910, 2010.

[42] H. M. Cheng, L. C. Chiang, Y. M. Jan, G. W. Chen, and T. C. $\mathrm{Li}$, "The efficacy and safety of a Chinese herbal product (XiaoFeng-San) for the treatment of refractory atopic dermatitis: a randomized, double-blind, placebo-controlled trial," International Archives of Allergy and Immunology, vol. 155, no. 2, pp. 141-148, 2011.

[43] K. L. Hon, T. F. Leung, B. C. Ng et al., "Therapeutic effect and safety of a traditional Chinese medicine for atopic dermatitis in children: a randomized, double-blind, placebo-controlled study," Hong Kong Medical Journal, vol. 17, no. 2, pp. 38-40, 2012.

[44] F. Pfab, G. I. Athanasiadis, J. Huss-Marp et al., "Effect of acupuncture on allergen-induced basophil activation in patients with atopic eczema: a pilot trial," Journal of Alternative and Complementary Medicine, vol. 17, no. 4, pp. 309-314, 2011.

[45] M. G. Xiu and D. F. Wang, "Observation on therapeutic effect of acupoint injection desensitization with autoblood on chronic urticaria," Chinese Acupuncture, vol. 31, no. 7, pp. 610-612, 2011.

[46] I. H. Choi, S. Kim, Y. Kim, and Y. Yun, "The effect of TJ15 Plus TJ-17 on atopic dermatitis: a pilot study based on the principle of pattern identification," Journal of Alternative and Complementary Medicine, vol. 18, no. 6, pp. 576-582, 2012.

[47] K. C. Lee, A. Keyes, J. R. Hensley et al., "Effectiveness of acupressure on pruritus and lichenifi cation associated with atopic dermatitis: a pilot trial," Acupuncture in Medicine, vol. 30, no. 1, pp. 8-11, 2012.

[48] F. Pfab, M.-T. Kirchner, J. Huss-Marp et al., "Acupuncture compared with oral antihistamine for type i hypersensitivity itch and skin response in adults with atopic dermatitis-a patient- and examiner-blinded, randomized, placebo-controlled, crossover trial," Allergy, vol. 67, no. 4, pp. 566-573, 2012.

[49] C. X. Wu, N. Li, and Z. H. Xu, "Effects of yiqi huoxue qufeng decoction on the diamine oxidase and immunoglobin $\mathrm{E}$ of patients with chronic urticarial," Chinese Journal of Integrative Medicine, vol. 32, no. 9, pp. 1216-1218, 2012.

[50] X. H. Quan, S. Cheng, H. Ma et al., "Combination of flying needle with Chinese Herbal Medicine in the treatment of Atopic dermatitis: a clinical trial," Pakistan Journal of Pharmaceutical Sciences, vol. 27, no. 5, pp. 1689-1690, 2014.

[51] J. Liu, X. Mo, D. Wu et al., "Efficacy of a Chinese herbal medicine for the treatment of atopic dermatitis: a randomised controlled study," Complementary Therapies in Medicine, vol. 23, no. 5, pp. 644-651, 2015.

[52] M. Mehrbani, R. Choopani, A. Fekri, M. Mehrabani, M. Mosaddegh, and M. Mehrabani, "The efficacy of whey associated with dodder seed extract on moderate-to-severe atopic dermatitis in adults: a randomized, double-blind, placebo-controlled clinical trial," Journal of Ethnopharmacology, vol. 172, pp. 325-332, 2015.
[53] C.-Y. Yen and C.-L. Hsieh, "Therapeutic effect of Tzu-Yun ointment on patients with atopic dermatitis: a preliminary, randomized, controlled, open-label study," Journal of Alternative and Complementary Medicine, vol. 22, no. 3, pp. 237-243, 2016.

[54] M. Egger, S. G. Davey, M. Schneider, and C. Minder, "Bias in meta-analysis detected by a simple, graphical test," British Medical Journal, vol. 315, no. 7129, pp. 629-634, 1997.

[55] K. L. Hon, B. C. Chan, and P. C. Leung, "Chinese herbal medicine research in eczema treatment," Chinese Medicine, vol. 6, article 17, 2011.

[56] J. A. Ellison, L. Patel, D. W. Ray, T. J. David, and P. E. Clayton, "Hypothalamic-pituitary-adrenal function and glucocorticoid sensitivity in atopic dermatitis," Pediatrics, vol. 105, pp. 794-799, 2000.

[57] L. Y. Chung, "Antioxidant profiles of a prepared extract of Chinese herbs for the treatment of atopic eczema," Phytotherapy Research, vol. 22, no. 4, pp. 493-499, 2008.

[58] C. Dinicola, A. Kekevian, and C. Chang, "Integrative medicine as adjunct therapy in the treatment of atopic dermatitis-the role of traditional Chinese medicine, dietary supplements, and other modalities," Clinical Reviews in Allergy and Immunology, vol. 44, no. 3, pp. 242-253, 2013.

[59] Dermatology department for academy of Traditional Chinese Medicine (TCM), "The TCM expert consensus of AD treating plan," Chinese Journal of Dermatovenereology of Integrated Traditional and Western Medicine, vol. 12, no. 1, pp. 60-61, 2013.

[60] J.-B. Han, C. W. Kim, B. Sun et al., "The antipruritic effect of acupuncture on serotonin-evoked itch in rats," Acupuncture and Electro-Therapeutics Research, vol. 33, no. 4, pp. 145-156, 2008. 


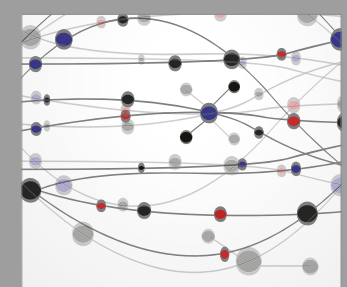

The Scientific World Journal
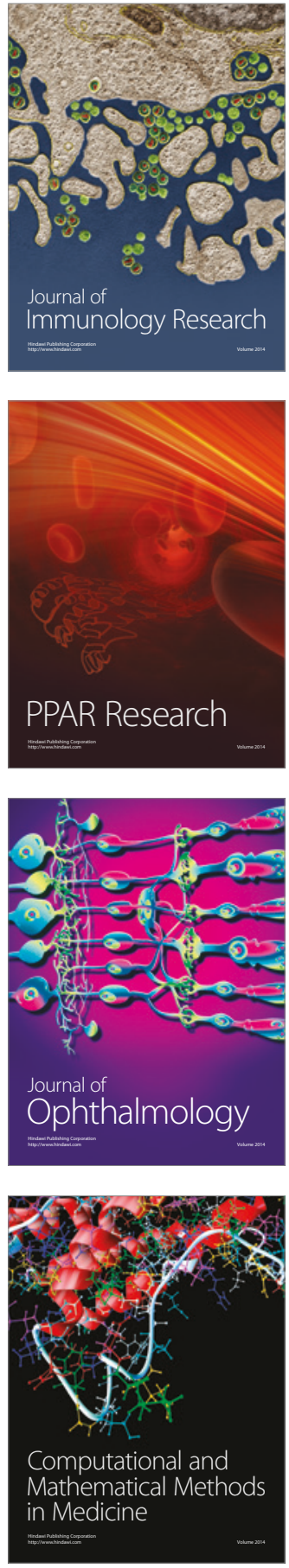

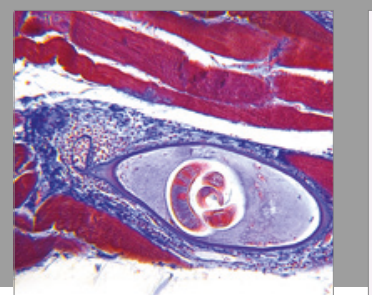

Gastroenterology Research and Practice
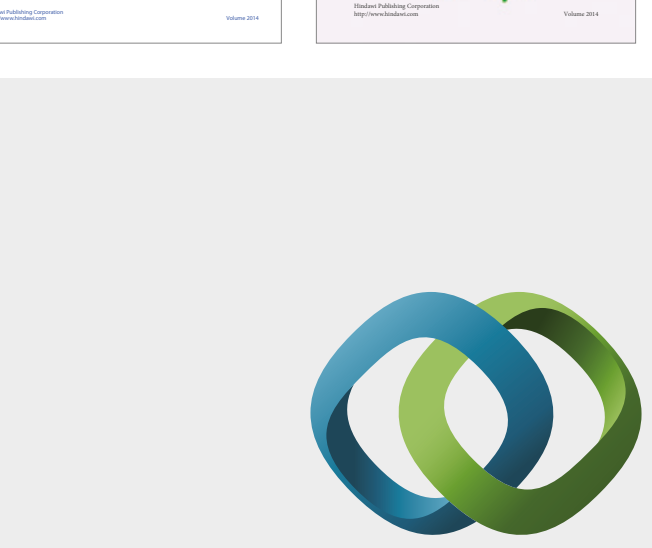

\section{Hindawi}

Submit your manuscripts at

https://www.hindawi.com
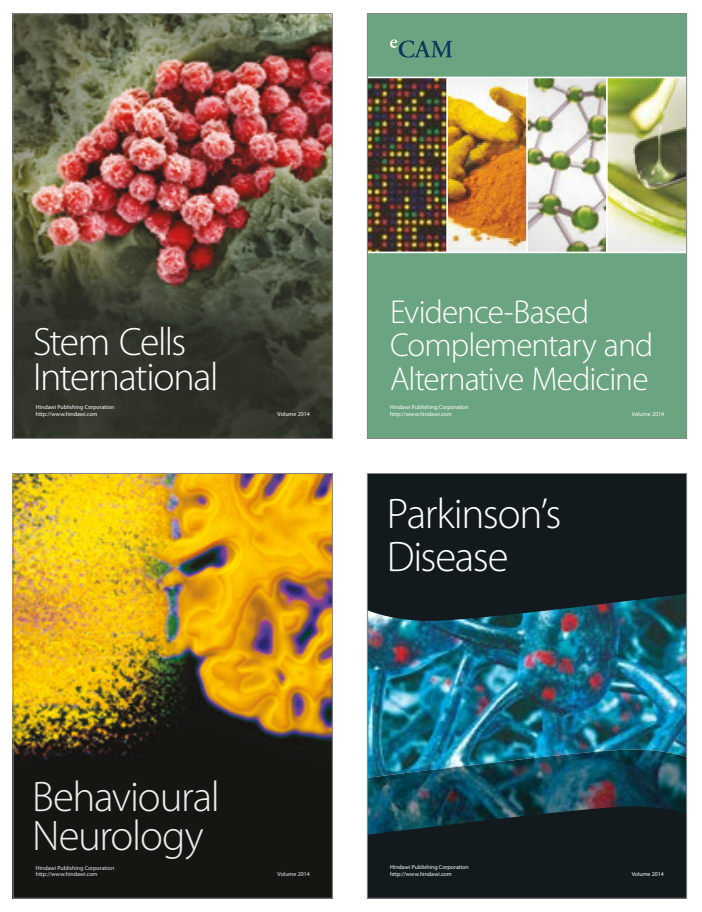
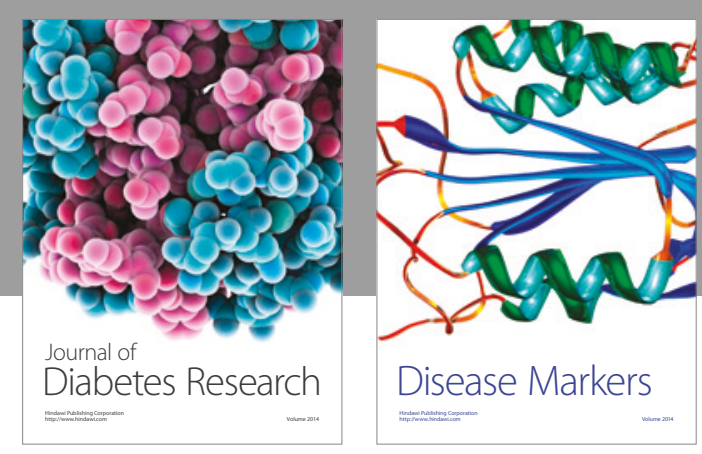

Disease Markers
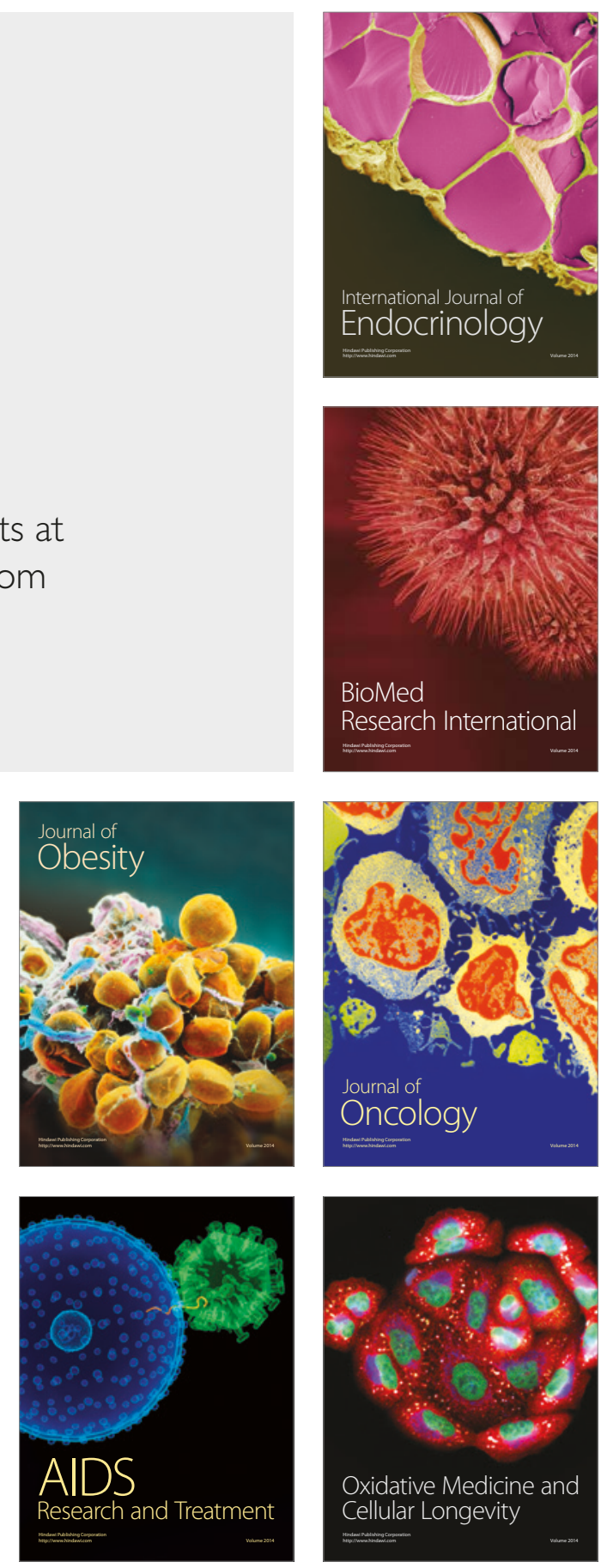